\title{
The salivary gland transcriptome of the neotropical malaria vector Anopheles darlingi reveals accelerated evolution of genes relevant to hematophagy
}

\author{
Eric Calvo ${ }^{1}$, Van M Pham ${ }^{1}$, Osvaldo Marinotti ${ }^{2}$, John F Andersen ${ }^{1}$ and \\ José MC Ribeiro*1
}

Address: ${ }^{1}$ Section of Vector Biology, Laboratory of Malaria and Vector Research, National Institute of Allergy and Infectious Diseases, National Institutes of Health, Rockville, MD 20852, USA and 2Department of Molecular Biology and Biochemistry, University of California, Irvine, CA 92697-3900, USA

Email: Eric Calvo - eric.calvo@fda.hhs.gov; Van M Pham - vpham@niaid.nih.gov; Osvaldo Marinotti - omarinot@uci.edu; John F Andersen - jandersen@niaid.nih.gov; José MC Ribeiro* - jribeiro@niaid.nih.gov

* Corresponding author

Published: 29 January 2009

BMC Genomics 2009, 10:57 doi:10.1186/147|-2164-10-57
Received: 4 November 2008

Accepted: 29 January 2009

This article is available from: http://www.biomedcentral.com/I47/-2/64/10/57

(c) 2009 Calvo et al; licensee BioMed Central Ltd.

This is an Open Access article distributed under the terms of the Creative Commons Attribution License (http://creativecommons.org/licenses/by/2.0), which permits unrestricted use, distribution, and reproduction in any medium, provided the original work is properly cited.

\begin{abstract}
Background: Mosquito saliva, consisting of a mixture of dozens of proteins affecting vertebrate hemostasis and having sugar digestive and antimicrobial properties, helps both blood and sugar meal feeding. Culicine and anopheline mosquitoes diverged 150 MYA, and within the anophelines, the New World species diverged from those of the Old World 95 MYA. While the sialotranscriptome (from the Greek sialo, saliva) of several species of the Cellia subgenus of Anopheles has been described thoroughly, no detailed analysis of any New World anopheline has been done to date. Here we present and analyze data from a comprehensive salivary gland (SG) transcriptome of the neotropical malaria vector Anopheles darlingi (subgenus Nyssorhynchus).

Results: A total of 2,37I clones randomly selected from an adult female An. darlingi SG cDNA library were sequenced and used to assemble a database that yielded 966 clusters of related sequences, 739 of which were singletons. Primer extension experiments were performed in selected clones to further extend sequence coverage, allowing for the identification of 183 protein sequences, II 4 of which code for putative secreted proteins.

Conclusion: Comparative analysis of sialotranscriptomes of An. darlingi and An. gambiae reveals significant divergence of salivary proteins. On average, salivary proteins are only $53 \%$ identical, while housekeeping proteins are $86 \%$ identical between the two species. Furthermore, An. darlingi proteins were found that match culicine but not anopheline proteins, indicating loss or rapid evolution of these proteins in the old world Cellia subgenus. On the other hand, several well represented salivary protein families in old world anophelines are not expressed in An. darlingi.
\end{abstract}

\section{Background}

Saliva of hematophagous arthropods contain a vast array of compounds that disarm their hosts' hemostasis and inflammation, thus helping to obtain a blood meal [1,2]. In the case of mosquitoes and other blood-sucking Nematocera, saliva also helps ingestion of sugar meals, in the 
form of carbohydrate hydrolysing enzymes [3]. Antimicrobial products, in the form of pattern recognition proteins, serine proteases, and antimicrobial peptides (AMPs), are also routinely found in the saliva of hematophagous arthropods; these may protect the blood or sugar meal from harmful microbial growth [2].

Detailed sialotranscriptomes of several mosquito species [4-13] are revealing their salivary composition to include a number of proteins of previously known families as well as completely novel families unique to mosquitoes or their close relatives among the hematophagous Nematocera. In particular, studies done with Culex quinquefasciatus [8], Aedes aegypti [7], and Anopheles gambiae [13], for which the genomes are known, indicate that the mosquito salivary cocktail consists of 60-100 secreted proteins, several of which are members of multigene families. In these studies, Aedes-, Anopheles-, and Culex-specific proteins were discovered. Most of the salivary proteins do not have a known function but presumably affect hemostasis, inflammation, and sugar digestion or have antimicrobial activity.

Within the Anopheles genus, sialotranscriptomes were described for An. gambiae [11-13], An. funestus [6], and An. stephensi [9], all members of the same subgenus Cellia. These studies allowed the discovery of species-specific proteins and, importantly, that the salivary proteins among members of the same subgenus are very divergent when compared to housekeeping proteins, perhaps due to immune pressure of their vertebrate hosts, in the case of antihemostatic or antiinflammatory proteins, or of microbial resistance, in the case of antimicrobial products [9]. An. darlingi (subgenus Nyssorhynchus) is an important vector of human malaria in Central and South America, and, like all non-autogenous mosquitoes, adult females absolutely require a blood meal to develop eggs, preferring humans to other blood sources [14]. Preliminary studies with An. darlingi salivary glands identified one salivary lysozyme [15] and a limited proteomic work identified three additional salivary proteins [16]. Additionally, a salivary transcriptome of An. darlingi was previously described [5], but no protein sequences were extracted from that expressed sequence tag (EST) set. In the present work, we increased the An. darlingi salivary EST set from 593 to 2,371 and extracted and deposited 183 protein sequences to GenBank, 114 of which represent putative salivary secreted proteins (inclusive of alleles). This new set of proteins reveals novel proteins as well as protein families that were previously found only in Culex, thus pointing to their existence at 150 MYA, when a common ancestor existed to culicine and anophelines [17] and that these protein families were lost in the genus Aedes and the Cellia anopheline subgenus. Accordingly, the complex and varied evolution of salivary proteins in mosquitoes is being revealed at the same time that new protein families with potentially novel pharmacologic activities are being discovered.

\section{Results and Discussion}

\section{Characteristics of the assembled salivary EST set}

A total of 2,371 cDNA clones were used to assemble a database [see additional file 1] that yielded 966 clusters of related sequences, 739 of which contained only one EST. This dataset included the 593 sequences used in our previous work [5]. The 966 clusters were compared, using the programs blastx, blastn, or RPS-BLAST [18], to the nonredundant (NR) protein database of the National Center of Biological Information (NCBI), National Library of Medicine, NIH, to a gene ontology database [19], to the conserved domains database of the NCBI [20], and to a custom prepared subset of the NCBI nucleotide database containing either mitochondrial or rRNA sequences.

Three categories of expressed genes derived from the manual annotation of the contigs (Fig. 1). The putatively secreted (S) category contained $50 \%$ of the sequences, the housekeeping $(\mathrm{H})$ category had 34 , and $16 \%$ of the ESTs could not be classified and belong to the unknown (U) class. The transcripts of the $U$ class could represent novel proteins or derive from the less conserved 3' or 5' untranslated regions of genes, as was indicated for the sialotranscriptome of An. gambiae [13].

\section{Housekeeping $(H)$ genes}

The 797 ESTs attributed to $\mathrm{H}$ genes expressed in the salivary glands (SGs) of An. darlingi were further character-

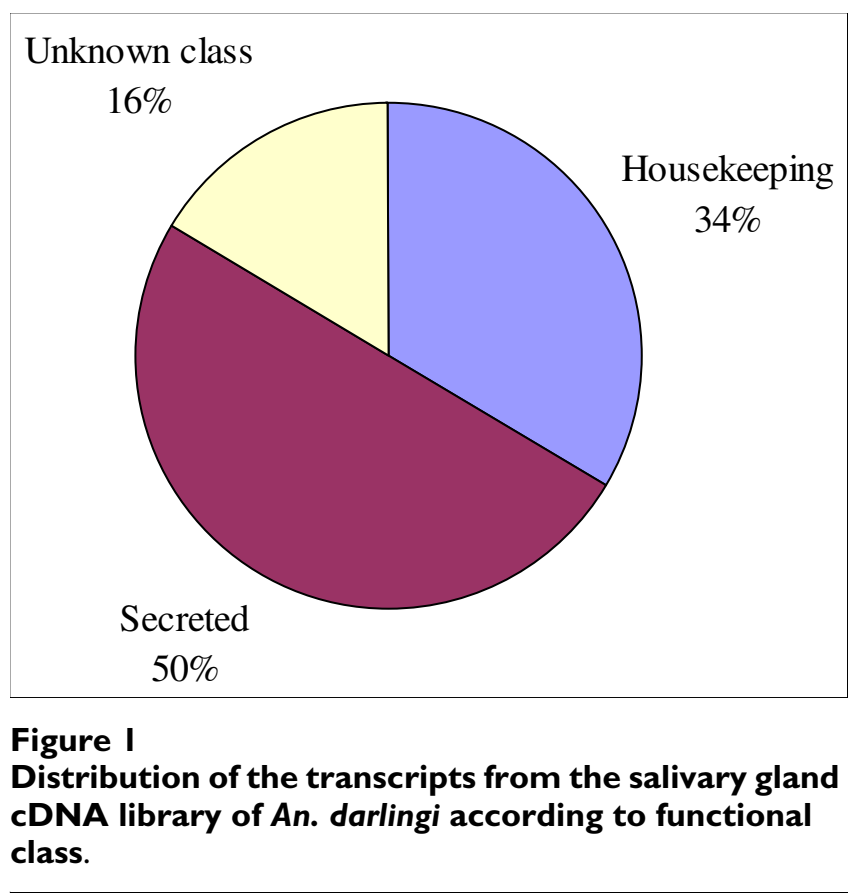


ized into 19 subgroups according to function (Table 1 and additional file 1). Transcripts associated with the protein synthesis machinery represented $53 \%$ of all transcripts associated with a housekeeping function, an expected result for the secretory nature of the organ. Energy metabolism accounted for $10 \%$ of the transcripts. Twenty percent of the transcripts were classified as either 'Unknown conserved' or 'Conserved secreted' proteins. These represent highly conserved proteins of unknown function, presumably associated with cellular function but still uncharacterized. These sets may help functional identification of the 'Conserved hypothetical' proteins as previously reviewed in [21].

\section{Possibly secreted (S) class of expressed genes}

A total of 1,188 ESTs represent putative An. darlingi salivary components (Table 2 and Supplemental Table S1). These include previously known gene families as well as novel proteins. Table 2 also indicates our degree of knowledge, or ignorance, regarding these protein families, for 22 of which we have no hint for function. Many of these putatively secreted protein families of unknown function are multigenic, such as the SG1 and antigen- 5 families, for example. The D7/OBP-like and aegyptin/30-kDa families contribute to $30 \%$ of all transcripts associated with secreted products. This is in line with these proteins accounting for the most intensely stained bands in SDS gels of mosquito salivary homogenates [4,7-10]. The identification of $8 \%$ of the transcripts with antimicrobial polypeptides is exceptional. Possibly this high level of expression, when compared with previous mosquito sialotranscriptomes, derives from the fact the An. darling $i$ used in this work were captured from the field and, as such, they could have been more exposed to pathogens than the laboratory-reared insects used to originate other mosquito salivary transcriptomes. Mosquito age could have been another possible variable, as the laboratoryreared mosquitoes had their glands removed in the first two days after emergence, while the ages of captured An. darlingi could not be specified but were most likely older than two days.

\section{The salivary secretome of Anopheles darlingi}

From the sequenced cDNAs, a total of 183 novel An. darlingi protein sequences was derived, 114 of which code for putative secreted products (Table 2, Table 3, and additional file 2). Table 3 presents a summary of the secreted subset, with links to GenBank.

\section{Proteins with presumed or experimentally validated function \\ The D7/Odorant-binding protein-like family}

The first D7 protein was cloned from a cDNA library from adult female Ae. aegypti SGs. It had an appropriately cryptic name because, at the time, it did not match other known proteins and its function was thus unknown [22]. Additional members of this family were later described in An. gambiae, other mosquito species, and also in sand flies $[11,23,24]$. In these insects, salivary D7 proteins are encoded by multiple genes, and short and long versions of this protein family were recognized. The D7 protein family was then identified to be a member of the odorant-

Table I: Classification of transcripts associated with housekeeping function

\begin{tabular}{|c|c|c|}
\hline Class & Number of transcripts & Percent of housekeeping group \\
\hline Protein synthesis machinery & 429 & 53.8 \\
\hline Unknown conserved & 114 & 14.3 \\
\hline Energy metabolism & 79 & 9.9 \\
\hline Conserved secreted proteins & 37 & 4.6 \\
\hline Protein modification machinery & 23 & 2.9 \\
\hline Signal transduction & 22 & 2.8 \\
\hline Proteasome machinery & 20 & 2.5 \\
\hline Protein export machinery & 15 & 1.9 \\
\hline Transcription machinery & 11 & $\mathrm{I} .4$ \\
\hline Transporter/storage & 10 & 1.3 \\
\hline Carbohydrate metabolism & 8 & 1.0 \\
\hline Cytoskeletal & 8 & 1.0 \\
\hline Nuclear regulation & 6 & 0.8 \\
\hline Secondary products metabolism & 6 & 0.8 \\
\hline Amino acid metabolism & 4 & 0.5 \\
\hline Lipid metabolism & 2 & 0.3 \\
\hline Nucleotide metabolism & I & 0.1 \\
\hline Intermediary metabolism & 1 & 0.1 \\
\hline Extracellular matrix and adhesion & 1 & 0.1 \\
\hline Total & 797 & \\
\hline
\end{tabular}


Table 2: Classification of transcripts associated with secreted products

\begin{tabular}{|c|c|c|}
\hline \multicolumn{3}{|l|}{ Class } \\
\hline Subclass & Number of transcripts & Percent of secreted group \\
\hline \multicolumn{3}{|l|}{ Secreted, known function } \\
\hline $\mathrm{D} 7 / \mathrm{OBP}$ & 269 & 22.6 \\
\hline Aegyptin/30-kDa antigen & 98 & 8.2 \\
\hline Anophelin & 20 & 1.7 \\
\hline gSG8/Kazal & 14 & 1.2 \\
\hline \multicolumn{3}{|l|}{ Immunity } \\
\hline Pattern recognition & 5 & 0.4 \\
\hline Antimicrobials & 92 & 7.7 \\
\hline \multicolumn{3}{|l|}{ Enzymes } \\
\hline Glycosidases & 41 & 3.5 \\
\hline Serine proteases & 5 & 0.4 \\
\hline Apyrase/5' Nucleotidase & 22 & 1.9 \\
\hline Peroxidase & 4 & 0.3 \\
\hline \multicolumn{3}{|l|}{ Mucins } \\
\hline gSG3 family & 91 & 7.7 \\
\hline gSGIO & 12 & 1.0 \\
\hline 13.5-kDa family & 40 & 3.4 \\
\hline Other mucins & 39 & 3.3 \\
\hline \multicolumn{3}{|l|}{ Secreted, unknown function } \\
\hline SGI family & 63 & 5.3 \\
\hline SG2 family & 74 & 6.2 \\
\hline SG7 family & 16 & 1.3 \\
\hline SG5 family & 9 & 0.8 \\
\hline Antigen-5 family & 42 & 3.5 \\
\hline $56-\mathrm{kDa}$ family & 5 & 0.4 \\
\hline Acidic protein family & 32 & 2.7 \\
\hline Anopheline 6.3-kDa family & 11 & 0.9 \\
\hline Anopheline $8.2-\mathrm{kDa}$ family & 58 & 4.9 \\
\hline Anopheline hyp I5/17 family & 44 & 3.7 \\
\hline Basic tail mosquito family & 32 & 2.7 \\
\hline Culex I4.5-kDa family & 2 & 0.2 \\
\hline Culicidae 23.4-kDa family & 1 & 0.1 \\
\hline Culicine 4I.9-kDa family & 17 & 1.4 \\
\hline Other II families & 30 & 2.5 \\
\hline Total & 1188 & \\
\hline
\end{tabular}

binding protein (OBP) superfamily [25], the long versions containing two and the short versions containing one OBP domain. Because insect OBP are known to bind and carry lipophylic compounds such as odorants and pheromones, the potential function of D7 proteins was proposed to be related to binding one or more agonists of hemostasis and thus help blood feeding [23]. This prediction was confirmed when the short D7 proteins from $A n$. gambiae and the carboxy terminal domain of the long D7 of Ae. aegypti were found to bind biogenic amines with high affinity [26]. More recently, the amino terminal OBP domain of a D7 long form of Ae. aegypti was shown to bind peptidic leukotrienes with high affinity. The crystal structures of a short D7 protein from An. gambiae and a long D7 protein from Ae. aegypti revealed that the D7 OBP domains have seven alpha helices, two more than the canonical OBP family [27]. In addition to these inflam- matory agonist-binding functions, a short D7 protein from An. stephensi, named hamadarin, was shown to inhibit bradykinin formation by inhibiting the FXII/Kallikrein pathway [28].

An. gambiae has three genes coding for long D7 proteins and five coding for the short proteins, arranged in a single contiguous gene cassette in chromosome 3R [13]. We will refer below to these proteins from An. gambiae by the transcriptional order that their genes appear in chromosome 3R. Twelve An. darlingi proteins exhibiting sequence similarity to proteins from the D7 family were identified (Table 2 and Supplemental Table S2). These include five pairs that are more than 95\% identical to each other and are probably alleles. Accordingly, at least six unique products from the D7 family are identifiable in the An. darlingi salivary transcriptome. The alignment and phylogram of 
Table 3: Putative secreted proteins deducted from the salivary transcriptome analysis

\begin{tabular}{|c|c|c|}
\hline Name and link to protein sequence & NCBI number & Description \\
\hline \multicolumn{3}{|l|}{ Secreted, known or presumed function } \\
\hline \multicolumn{3}{|l|}{ D7/OBP protein family } \\
\hline AD-98 & 208657501 & short form D7 salivary protein \\
\hline AD-82 & 208657481 & SHORT FORM D7 SALIVARY PROTEIN \\
\hline$A D-81$ & 208657479 & SHORT AD Clade D7 SALIVARY PROTEIN \\
\hline AD-32 & 208657493 & D7 short \\
\hline$A D-31$ & 208657495 & SHORT AD Clade D7 SALIVARY PROTEIN \\
\hline AD-97 & 208657497 & SHORT AD Clade D7 SALIVARY PROTEIN \\
\hline AD-395 & 208657489 & Short D7 protein \\
\hline AD-394 & 208657487 & Short D7 protein \\
\hline$A D-I$ & 16798386 & AF427696_I D7-RELATED 3.2 PROTEIN \\
\hline$A D-3$ & 16798386 & D7-related 3.2 protein \\
\hline$A D-118$ & 208657499 & Long form D7 salivary protein \\
\hline$A D-560$ & 208657485 & Odorant binding protein \\
\hline \multicolumn{3}{|l|}{$30 \mathrm{kDa} / \mathrm{GE}$ rich/Aegyptin family } \\
\hline AD-24 & 208657597 & GE rich family salivary gland protein \\
\hline AD-26 & 208657599 & $30 \mathrm{kDa}$ salivary antigen family protein \\
\hline$A D-27$ & $20865760 I$ & GE rich salivary gland protein \\
\hline$A D-21$ & 208657603 & GE rich salivary gland protein \\
\hline$A D-22$ & 208657605 & GE rich salivary gland protein \\
\hline$A D-23$ & 208657607 & $30 \mathrm{kDa}$ salivary antigen family \\
\hline AD-25 & 208657609 & GE rich salivary gland protein \\
\hline$A D-28$ & 208657617 & $30 \mathrm{kDa}$ salivary antigen family protein \\
\hline
\end{tabular}

\section{Anophelin anti-thrombin}

\begin{tabular}{lll}
\hline AD-99 & 208657573 & salivary anti-thrombin peptide anophelin \\
\hline AD-100 & 208657579 & salivary anti-thrombin peptide anophelin \\
\hline gSG7/Anophensin family & & \\
\hline AD-133 & 208657683 & gSG7 salivary protein \\
\hline
\end{tabular}


Table 3: Putative secreted proteins deducted from the salivary transcriptome analysis (Continued)

\begin{tabular}{lll}
\hline AD-134 & 208657689 & gSG7 salivary protein \\
\hline AD-135 & 20865769I & gSG7 salivary protein
\end{tabular}

\section{Kazal domain}

\begin{tabular}{lll}
\hline AD-417 & 208657693 & Kazal domain-containing peptide \\
\hline AD-257 & 208657737 & Kazal domain-containing peptide \\
\hline AD-350 & 208657834 & Kazal domain-containing peptide \\
\hline
\end{tabular}

\section{Mucins}

SG3 family

\begin{tabular}{lll}
\hline AD-10 & 208657477 & SG3 PROTEIN \\
\hline AD-9 & 20865768 I & sg3 protein \\
\hline AD-7 & 208657687 & sg3 protein \\
\hline AD-8 & 208657697 & SG3 PROTEIN \\
\hline gSG I0 family & & \\
\hline AD-143 & 208657645 & gSG I0 salivary mucin \\
\hline AD-146 & 208657647 & gSG I0 salivary mucin \\
\hline AD-145 & $20865765 I$ & gSG I0 salivary mucin
\end{tabular}

\section{I3.5 kDa family}

\begin{tabular}{lll}
\hline AD-45 & 208657695 & mucin-like protein \\
\hline AD-46 & 208657701 & mucin-like protein \\
\hline AD-43 & 208657713 & PUTATIVE I3.5 KDA SALIVARY PROTEIN \\
\hline AD-42 & 20865772 I & putative I3.5 kDa salivary protein \\
\hline AD-44 & 208657723 & PUTATIVE I3.5 KDA SALIVARY PROTEIN \\
\hline AD-4I & 208657733 & PUTATIVE I3.5 KDA SALIVARY PROTEIN \\
\hline AD-47 & 208657751 & mucin-like protein \\
\hline Other mucins & 208657473 & hypothetical secreted peptide precursor \\
\hline AD-II & 208657465 & putative salivary secreted mucin 3 - fragment - similar to virus induced protein \\
\hline AD- I9I & & \\
\hline Peritrofins & 208657765 & mucin-like peritrophin \\
\hline AD-873 & & \\
\hline
\end{tabular}


Table 3: Putative secreted proteins deducted from the salivary transcriptome analysis (Continued)

\section{Enzymes}

Apyrase/5' nucleotidase

\begin{tabular}{lll}
\hline IS07-104 & 208657633 & putative 5' nucleotidase/apyrase \\
\hline AD- I0I & 208657659 & salivary apyrase - truncated at 5 prime \\
\hline Peroxidase & & \\
\hline AD-573 & 208657575 & salivary peroxidase
\end{tabular}

\section{Maltase}

AD-70

2086576 II probable salivary maltase precursor

Serine protease

AD-698 $208657483 \quad$ CLIP-domain serine protease subfamily D - truncated at 5 prime

Immunity related products

\section{Gambicin}

\begin{tabular}{|cll}
\hline AD-23I & 20865764I & GAMBICIN PRECURSOR \\
\hline Defensin & & \\
\hline AD-124 & 20865773 I & defensin \\
\hline Cecropin & & \\
\hline AD-57 & 208657655 & antimicrobial peptide cecropin \\
\hline AD-236 & 208657739 & antimicrobial peptide cecropin \\
\hline AD-927 & 208657741 & Cecropin precursor \\
\hline
\end{tabular}

Peptidoglycan recognition protein

\begin{tabular}{lll}
\hline AD-457 & 208657711 & peptidoglycan recognition protein \\
\hline Lysozyme & & \\
\hline AD- 174 & 208657469 & lysozyme \\
\hline AD- 175 & 208657471 & lysozyme
\end{tabular}

Gly His rich peptide

AD-259 $208657749 \quad$ hypothetical secreted protein with GHG repeats

Secreted, unknown function

Promiscuous families 
Table 3: Putative secreted proteins deducted from the salivary transcriptome analysis (Continued)

\begin{tabular}{|c|c|c|}
\hline \multicolumn{3}{|c|}{ Antigen 5 family } \\
\hline AD-38 & 33359651 & Antigen 5-related 2 \\
\hline AD-430 & 208657475 & antigen 5 -related 2 protein \\
\hline \multicolumn{3}{|c|}{ Mosquito specific families } \\
\hline \multicolumn{3}{|c|}{ gSG5 family } \\
\hline AD- 196 & 208657685 & conserved secreted mosquito protein \\
\hline \multicolumn{3}{|c|}{ gSG8 } \\
\hline AD- 178 & 208657639 & short gSG8-like protein \\
\hline \multicolumn{3}{|c|}{ Basic tail family } \\
\hline AD-217 & 208657667 & putative salivary secreted peptide \\
\hline$A D-216$ & 208657679 & putative salivary secreted peptide \\
\hline \multicolumn{3}{|c|}{$4.3 \mathrm{kDa}$ family } \\
\hline AD-476 & 208657709 & putative $4.3 \mathrm{kDa}$ secreted salivary peptide \\
\hline \multicolumn{3}{|c|}{ Proline rich secreted polypeptide } \\
\hline AD-267 & 208657677 & proline rich salivary secreted peptide \\
\hline \multicolumn{3}{|c|}{ Culicine 41.9 kDa family } \\
\hline$A D-I I I$ & 208657783 & PUTATIVE 4 I.9 KDA BASIC SALIVARY PROTEIN - truncated at 5 prime \\
\hline AD- 112 & 208657807 & putative $41.9 \mathrm{kDa}$ basic salivary protein - truncated at 5 prime \\
\hline$A D-114$ & 208657821 & 4I kDa family salivary secreted protein \\
\hline \multicolumn{3}{|c|}{ SG I family } \\
\hline AD- 159 & 208657649 & SGI-like salivary protein \\
\hline AD- 160 & 208657653 & SGI-like salivary protein \\
\hline AD- 130 & 208657753 & GSGI PROTEIN \\
\hline AD-85 & 208657767 & PUTATIVE SALIVARY PROTEIN SGIB \\
\hline AD-86 & 208657777 & PUTATIVE SALIVARY PROTEIN SGI \\
\hline AD- 153 & 208657781 & TRIO salivary gland protein precursor - SGI family \\
\hline \multicolumn{3}{|c|}{ gSG2 family } \\
\hline AD-49 & 208657761 & hypothetical protein \\
\hline$A D-5 I$ & 208657819 & hypothetical secreted peptide precursor \\
\hline
\end{tabular}


Table 3: Putative secreted proteins deducted from the salivary transcriptome analysis (Continued)

\begin{tabular}{lll}
\hline AD-53 & 208657773 & hypothetical secreted peptide precursor \\
\hline AD-54 & 208657763 & hypothetical secreted peptide precursor \\
\hline AD-90 & 208657779 & putative secreted peptide of the $6 \mathrm{kDa}$ family \\
\hline AD-91 & 208657785 & putative secreted peptide of the $6 \mathrm{kDa}$ family \\
\hline AD-92 & 208657811 & putative secreted peptide of the $6 \mathrm{kDa}$ family \\
\hline AD-89 & 208657747 & putative secreted peptide of the $6 \mathrm{kDa}$ family \\
\hline AD-64 & 208657759 & putative secreted peptide of the $6 \mathrm{kDa}$ family
\end{tabular}

\begin{tabular}{lcr}
\hline \multicolumn{2}{c}{ Hyp I 5/I7 family } & \\
\hline AD-37 & 208657719 & hypothetical salivary protein I5 \\
\hline AD-35 & 208657727 & hypothetical salivary protein I5 \\
\hline AD-36 & 208657729 & hypothetical salivary protein I5
\end{tabular}

hyp8.2 kDa family

\begin{tabular}{lcc}
\hline AD-63 & 208657771 & hypothetical salivary protein 8.2 \\
\hline AD-96 & 208657815 & hypothetical salivary protein 8.2
\end{tabular}

hyp6.2 kDa family

AD-I47 20865766I putative secreted salivary basic peptide hyp6.2

hyp $5.6 \mathrm{kDa}$ family

\begin{tabular}{lll}
\hline AD-269 & 208657637 & hyp5.6 salivary basic secreted peptide \\
\hline 2WIRRP family & & \\
\hline AD-13 & 208657673 & hypothetical secreted protein \\
\hline AD-15 & 208657665 & 30 kDa salivary antigen family protein \\
\hline AD-12 & 208657669 & hypothetical secreted protein \\
\hline AD-14 & 208657671 & hypothetical secreted protein \\
\hline AD-19 & 208657675 & hypothetical secreted protein \\
\hline AD-18 & 208657717 & hypothetical secreted protein \\
\hline Other secreted peptides & & \\
\hline AD-136 & 208657830 & hypothetical conserved secreted protein \\
\hline AD-138 & 208657848 & hypothetical conserved secreted protein \\
\hline AD-119 & 208657797 & putative secreted peptide \\
\hline
\end{tabular}


these protein sequences with all the $\mathrm{D} 7$ protein sequences of An. gambiae reveal $i$ ) the existence of An. darlingi proteins that are uniquely shorter, indicated by the bar above the alignment (Fig. 2A), which form a robust clade named 'Short AD clade' in Figure 2B. This clade is most closely related to the short D7 proteins 1 and 4 from An. gambiae (Fig. 2B), as indicated by strong bootstrap support; ii) homologues of $A n$. gambiae short proteins 2 and 3 are identifiable (indicated as s2/s3 homologue in Fig. 2B), as well as the ortholog of the fifth short protein of An. gambiae; and iii) AD-118 represents an An. darlingi long D7 protein that is related to An. gambiae long D7 proteins 1 and 2.

$\mathrm{AD}-1$ and $\mathrm{AD}-3$, which possibly derive from a polymorphic gene, are similar to the D7s2 and D7s3 of An. gambiae. These proteins have in common a similar size as well as being the most transcribed D7 proteins in both species [13]. AD-1 and AD-3, but not the other An. darlingi D7 sequences, share an amino acid (aa) pattern, included in

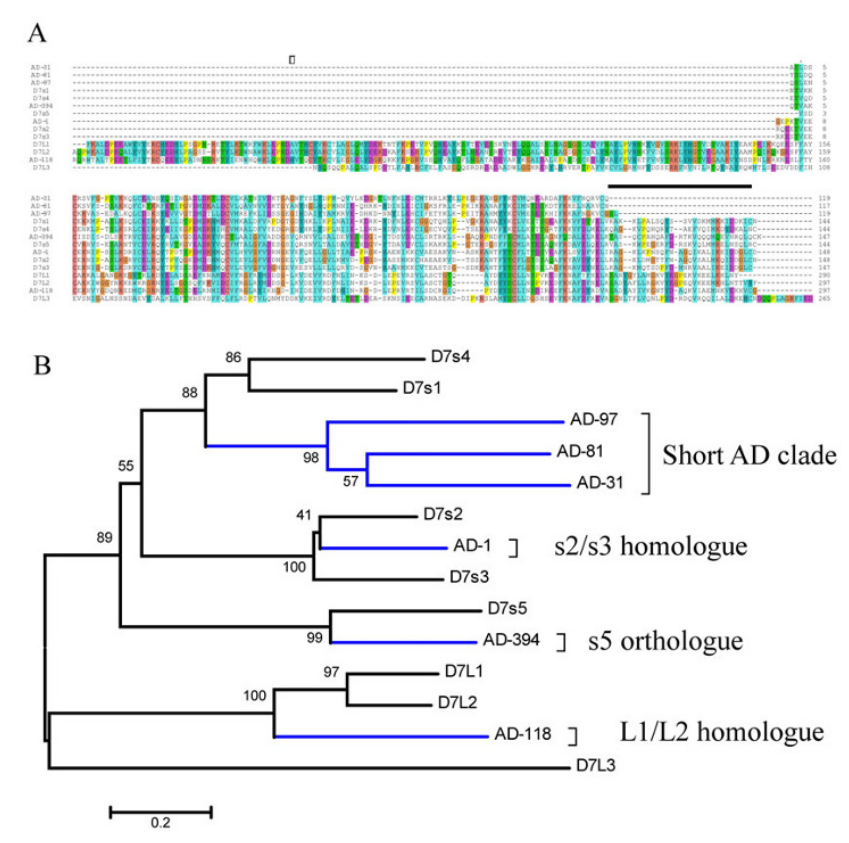

Figure 2

The D7 protein family of An. darlingi and An. Gambiae. (A) Clustal alignment. (B) Phylogram based on the alignment in $(A)$. The numbers on the tree nodes represent the percent bootstrap support in 10,000 trials. The bar at the bottom indicates $20 \%$ amino acid divergence. The An. gambiae sequence names start with D7 followed by s or $L$ for short and long forms; the number following s or $L$ represents the order of the gene in the D7 chromosomal region, following its transcription direction. The An. darlingi sequences start with $A D$, followed by a number derived from the cluster number, as determined in Supplemental Table SI. For more details, see text. a cysteine framework, that are known from crystal structure to make contact with biogenic amines $[27,29]$. The high transcription of these gene products is in line with the large amounts of protein needed to scavenge biogenic amines that accumulate to the order of one micromolar in the host tissues [26], suggesting these An. darlingi proteins, likewise their An. gambiae homologues, function as biogenic amine scavengers.

D7s1 from An. gambiae, the homologue of An. stephensi hamadarin [28] has an alkaline pI of 9.22, contrasting with the neutral or acidic pI of the remaining short D7 proteins. To the extent this basic pI is associated with hamadarin function, it is worth noting that AD-81 and $\mathrm{AD}-31$ (Fig. 2) also have pIs above 8.5, but not the more distantly related AD-97. These three An. darlingi proteins are members of the novel short $\mathrm{AD}$ clade (Fig. 2B), which shares the same tree branch where D7s1 from An. gambiae are located, suggesting they could have a similar function as hamadarin.

\section{The 30-kDa antigen/GE-rich/aegyptin family}

This protein family, found exclusively in the SGs of adult female mosquitoes, was first identified as a salivary antigen in Ae. aegypti [30] and later found in salivary transcriptomes and proteomes of both culicine and anopheline mosquitoes [4,6-9,13,31,32], where it was named GE-rich protein. Proteomic work also indicated that this is one of the most abundant proteins in the SGs of mosquitoes. Its gene promoter has been used to specifically drive abundant gene expression in the SGs of transgenic mosquitoes [33]. More recently, proteins of this family from Aedes and Anopheles were shown to prevent platelet aggregation by collagen [34,35], indicating conservation of function after the split of the Culicidae into the culicines and anophelines, 150 MYA [17].

Analysis of the sialotranscriptome of An. darlingi allowed the identification of 8 protein sequences from this family, all represented by 2-17 ESTs found in the library. These protein sequences most probably reflect alleles from a single polymorphic gene, as they all share at least 95\% identity [36]. This degree of polymorphism is paralleled in the An. darlingi D7 proteins but is greater than that determined in sialotranscriptomes of other mosquitoes. Possibly this high degree of sequence variability reflects our material deriving from field-caught insects, whereas previous sialotranscriptomes were made with more genetically uniform mosquito colonies.

Alignment of all known members of this family, excluding those that are more than 95\% identical and of the same species, shows their structure clearly to be dominated by three domains [34]: the signal secretion peptide, a Gly/Glu-rich region, and a more conserved and organ- 
ized region where the block $\mathrm{T}-\mathrm{x}(29,30)-\mathrm{Q}-\mathrm{x}(5)-\mathrm{P}-$ $\mathrm{x}(13,15)-\mathrm{I}-\mathrm{x}(2)-\mathrm{C}-\mathrm{F}-\mathrm{x}(20)-\mathrm{C}-\mathrm{x}(8,10)-\mathrm{C}-\mathrm{x}(19,21)-\mathrm{C}$ can be identified (Fig. 3A). This block was used by the seedtop program http://www.ncbi.nlm.nih.gov/staff/tao/URLAPI/ seedtop.html to search over 6 million sequences of the NR database, only retrieving mosquito proteins. The phylogram (Fig. 3B) obtained from the alignment produces strong bootstrap support for three genus-specific clades, containing three genes for Ae. albopictus and Ae. aegypti, two for Culex quinquefasciatus, and one for each anopheline, An. stephensi, An. funestus, An. gambiae, An. darlingi, An. albimanus, and An. dirus. The An. darlingi protein groups, as expected, with An. albimanus, another American species from the Nyssorhynchus subgenus. Near the amino terminal of the mature sequences, the Nyssorhynchus-derived 30-kDa antigen/GE-rich sequences have an RGD motif as pointed out before for the An. albimanus sequence [32]; this triad is not found in similar proteins of other mosquitoes. RGD-containing peptides are commonly found in snake venoms [37] and tick saliva [38], and the motif itself is usually found surrounded by two

A

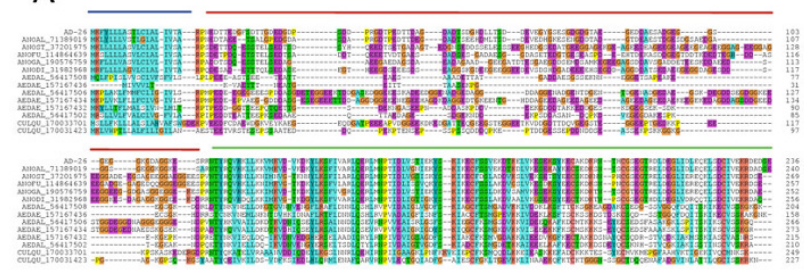

B

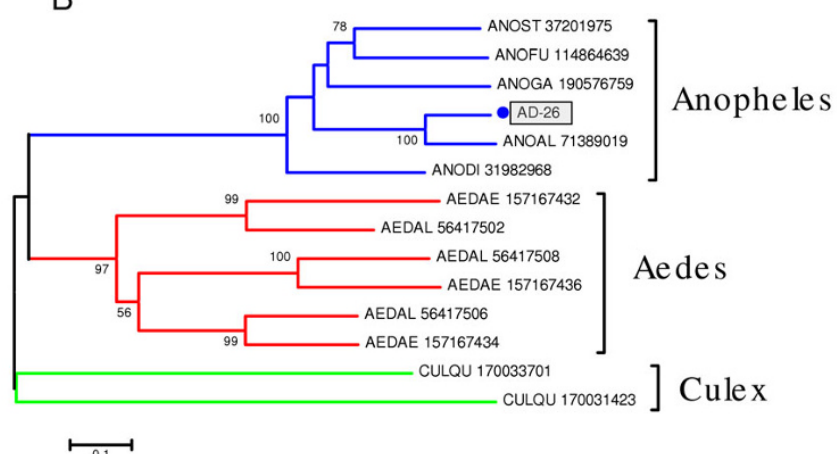

\section{Figure 3}

The 30-kD/GE-rich/Aegyptin protein family of mosquitoes. (A) Clustal alignment. (B) Phylogram based on the alignment in (A). The numbers on the tree nodes represent the percent bootstrap support in 10,000 trials (only values above $50 \%$ are shown). The bar at the bottom indicates $10 \%$ amino acid divergence. The sole An. darlingi sequence is identified by AD- 26 and a filled circle symbol. The remaining sequences are named with the first three letters from the genus name followed by two letters from the species name and by their $\mathrm{NCBI}$ protein accession number. For more details, see text. relatively close Cys groups that allow the RGD to be at the edge of a loop. This conformational feature permits the aa of the RDG motif to interact with integrins, disrupting platelet aggregation [39]. It is unknown, however, whether the RGD domain present in the 30-kDa antigen/ GE-rich proteins of Nyssorhynchus mosquitoes is structurally capable of interacting with integrins.

\section{Anophelin antithrombin}

The salivary anticlotting agent of An. albimanus, named anophelin, was previously characterized as a short acidic peptide with strong thrombin inhibitory activity $[40,41]$. Despite extensive sequencing of the salivary transcriptomes of many hematophagous arthropods, similar sequences are found only in sialotranscriptomes of anopheline mosquitoes. Two similar An. darlingi cDNAs, probably corresponding to alleles of a single gene, were identified. Conceptual translation of the gene results in acidic peptides of $6.3 \mathrm{kDa}$ and $\mathrm{pI}$ of 3.9 , which are $86 \%$ identical to An. albimanus anophelin [42].

\section{gSG7/Anophensin}

The gSG7 family is also unique to anophelines. In An. gambiae, it has two genes coding for gSG7 and gSG72, both of which are highly enriched in female SGs [13]. More recently, the An. stephensi homologue was determined to inhibit kallikrein and production of bradykinin, a pain-producing substance [43]. Four putative alleles representing the homologue(s) of gSG7/Anophensin in An. darlingi were identified. These An. darlingi SG transcripts, though, have no more than $45 \%$ identity to the An. gambiae gSG7 and An. stephensi anophensin [44].

\section{Kazal domain-containing peptides}

The Kazal domain is ubiquitously found in proteins of metazoan organisms and, accordingly, peptides containing this domain have been identified in studies of sialotranscriptomes and proteomes of tabanids $[45,46]$, triatomine bugs $[47,48]$, Culicoides sonorensis [49], and mosquitoes $[4,7,8]$. In Ae. aegypti and Ae. albopictus, the transcripts encoding Kazal domain proteins were ubiquitously expressed in all major organs analyzed, suggesting their function was not specific to blood feeding $[4,7]$. Kazal domain peptides have also been isolated and biochemically characterized from the midgut of triatomines, where they act as anticlotting agents [50-52], and from leech saliva, where they inhibit mast cell tryptase and plasmin [53-55]. Midgut transcriptomes of sand flies have also uncovered transcription of genes encoding peptides of this class [56,57]. In addition to their classical function as protease inhibitors, Kazal domain-containing peptides were identified as the salivary vasodilator of the horse flies Hybomitra bimaculata and Tabanus yao $[45,46]$. In An. darlingi, transcripts coding for three peptides with Kazal domain were found, yielding predicted mature MW of 
7.2-8.1 kDa and basic pI (8.3-9.4). AD-417 and AD-257 best match An. gambiae peptides when subjected to blastp against the NR database, albeit at only 45\% [58] and 44\% identity [59]. AD-350 best matches Aedes and Culex peptides at $47 \%$ and $51 \%$ identity [60]. The function of these salivary peptides in mosquitoes remains to be discovered.

\section{Mucins and Peritrophins}

Serine- and threonine-rich proteins are commonly found in sialotranscriptomes. These proteins are generally modified post translationally, and their mature forms have $\mathrm{N}$ acetyl galactosamine residues, typical of mucins [61]. They probably have a function to lubricate the food canals and may also have antimicrobial function. Several protein families are represented in this group, including those previously described as SG3, gSG10, and 13.5-kDa families. Peritrophins are proteins with a chitin-binding domain that are often found in sialotranscriptomes and may be related to the maintenance of the structure of the mouthparts and/or salivary canal.

The SG3 family in An. darlingi is highly expressed, four proteins of which account for 90 ESTs found in the cDNA library. They may be alleles or splice variants of a single gene [62], containing $29 \%$ to $32 \%$ Ser + Thr and over 47 predicted galactosylation sites in a mature $17-\mathrm{kD}$ a protein framework [63]. The An. darlingi SG3 has similarities only to other anopheline salivary proteins, having only $46 \%$ identity and $56 \%$ similarity to the closest relative, from An. funestus [64]. Compared to the Old World anophelines, the An. darlingi SG3 has a long GH repeat, which may confer zinc chelation capability and hence a putative antimicrobial activity for these proteins, because zinc chelation is characteristic of histidine rich antimicrobial agents that act by sequestration of this essential microbial growth factor [65-67].

The gSG10 family, containing three peptides (Supplemental Table S2), is represented by mature products with MW of $18 \mathrm{kDa}, 22 \%$ to $23 \% \mathrm{Ser}+\mathrm{Thr}$, and $15-20$ predicted galactosylation sites [68]. They also may be products of a single polymorphic and/or differentially spliced gene [69]. An. darlingi gSG10 members match both anopheline and culicine sequences of salivary origin [70], having a unique signature block [71]that characterizes these distinctive mosquito proteins.

The 13.5-kDa protein family is also represented in An. darlingi by the products of two or three genes [72]. Most mosquito $13.5-\mathrm{kDa}$ family members have over 30 predicted galactosylation sites [73]. An. funestus, An. gambiae, and $A n$. stephensi have recognizable relatives; however those proteins show only $41 \%$ to $44 \%$ identity over most of the length of the protein to the An. darlingi 13.5-kDa products. Culicine proteins that display only conservation of the stretch of threonine residues have been identified, but they may not be true homologues.

Two other putative mucins were found, AD-11 being a hypothetical secreted peptide of predicted mature MW of $3.8 \mathrm{kDa}, 25 \% \mathrm{Ser}+\mathrm{Thr}$, and ten potential glycosylation sites. No significant matches are found with other known proteins. AD-91, on the other hand, with $20 \%$ Ser + Thr content and 20 potential O-glycosylation sites, is $71 \%$ identical to an An. gambiae protein [74] that is related to a previously identified Aedes salivary protein and to a Drosophila protein annotated in the Gene Ontology database as associated with defense response to virus [75].

A single transcript in the An. darlingi sialotranscriptome codes for a peritrophin with a typical chitin-binding domain [76] and 69\% sequence identity to an An. gambiae protein annotated as peritrophin A [77], which was cloned from the mosquito midgut [78].

The SG3, SG10, and 13.5-kDa families were found abundantly expressed in sialotranscriptomes of adult male An. gambiae [78], indicating their function is likely not related specifically to blood feeding.

\section{Enzymes}

Enzymes associated with both blood (apyrase and peroxidase) and sugar (amylase and maltase) feeding are known to occur in mosquito saliva; accordingly, their corresponding transcripts have been found in mosquito sialotranscriptomes. Serine protease-encoding transcripts also are regularly found, but their proposed functions in helping blood feeding by interacting with host proteins or as participants in immune proteolytic cascades have not been validated.

Apyrase, which hydrolyses ATP and ADP to AMP and orthophosphates, has been a ubiquitous finding in the saliva of blood-sucking arthropods, where it destroys these important agonists of inflammation and platelet aggregation [2,79]. Mosquitoes have co-opted the 5' nucleotidase family to achieve this function [80-82]. Two genes of this family are expressed in the SGs of An. gambiae [13], named putative 5' nucleotidase and salivary apyrase, although both may function redundantly as apyrases. The sialotranscriptome of An. darlingi presents evidence for the two orthologues, IS07-44, a full-length orthologue of the salivary 5' nucleotidase of An. gambiae [83], to which it is $66 \%$ identical, and AD-101, which is a 5 ' truncated clone best matching the An. gambiae salivary apyrase [84].

A peroxidase was previously identified as the vasodilator for norepinephrine-induced aortic contractions found in An. albimanus SGs $[85,86]$. AD-573 encodes the full- 
length sequence of an An. darlingi salivary peroxidase that is $86 \%$ identical to An. albimanus and $52 \%$ identical to $A n$. gambiae salivary peroxidases [87]. This type of salivary vasodilator is so far unique to anopheline mosquitoes.

Maltase and amylases, as well as their transcripts, have been regularly found in the saliva and sialotranscriptomes of mosquitoes [88-91]. The first cloned gene from the SGs of any mosquito was actually a member of this family [92]. Ae. aegypti and An. gambiae express both genes in their SGs. Transcripts coding for both enzymes were found in the sialotranscriptome of An. darlingi [see additional file 1]. The full-length sequence for the orthologue of An. gambiae salivary maltase (68\% identity) [93] is presented in Supplemental Table S2.

Transcripts coding for at least two different serine proteases were found in An. darlingi sialotranscriptome [see additional file 1]. Supplemental Table S2 presents a truncated sequence of a CLIP domain serine protease expressed in An. darlingi SGs, $86 \%$ identical to the An. gambiae closest match [94].

\section{Immunity-related products}

Antimicrobial peptides, lysozyme, and pathogen pattern recognition polypeptides are commonly found in the sialotranscriptome of blood-sucking arthropods. Among the AMPs found in the sialotranscriptome of An. darlingi, a gambicin [95], a defensin [96], and three different cecropins [97] are described in their full-length condition. A peptidoglycan recognition protein, 94\% identical to an An. gambiae protein [98], is also reported as a full-length protein. Additionally, this study [see additional file 1] provides evidence for An. darlingi transcripts coding for Ctype lectins and ficolins, and an odd transcript having a full PMEI Pfam domain [99] normally found in plant proteins associated with inhibition of microbial pathogens' pectin methyl esterase. Two similar lysozyme cDNAs, probably products of alleles, are also described as fulllength polypeptides, matching 57\% identity to the closest An. gambiae protein [100]. Another identified lysozyme, contig 443 [101], corresponds to a previously described salivary An. darlingi lysozyme [15]. The occurrence of multiple lysozymes in the An. darlingi sialome is not surprising, as two lysozymes are expressed in the An. gambiae SGs [13].

With less certainty, we include in the immunity-related products the full-length sequence for a Gly-His-rich peptide that might have antimicrobial function by zinc chelation, as explained above. This protein matches a $C$. quinquefasciatus salivary peptide that also contains Gly repeats and a poly His in the amino terminus [102].

\section{Secreted proteins with unknown function}

Promiscuous antigen 5 (AG5) family

This is a ubiquitous protein family found in animals and plants [103] and in all sialotranscriptomes of blood-sucking Diptera analyzed so far. The function of these proteins in mosquito saliva is not known, although they were implicated in a proteolytic function in the venom of the marine snail Conus textile [104], in toxic functions in the saliva of a venomous lizard and snake venoms [105-109], and in an antifungal function in plants [110]. Remarkably, a member of this family acquired a typical RGD domain surrounded by Cys residues and acts as a main platelet aggregation inhibitor in the horsefly Tabanus yao [46]. Several genes from the AG5 family are transcribed in the SGs of mosquitoes, including some specific to the adult females and thus possibly associated with a specific function in blood feeding $[4,7,13]$. We present evidence, in the form of full-length transcripts, for the expression of at least two members of the AG5 family in An. darlingi SGs [111]. AD-38 matches with $67 \%$ identity the putative gVAG protein precursor of An. gambiae [112], a transcript enriched in the adult female SGs when compared with expression in other tissues [13]. AD-430 matches An. gambiae AG5-related 2 protein [113], which was shown to be ubiquitously expressed in adult female tissues [13]. The function(s) of this protein family in mosquitoes remain to be determined.

\section{Mosquito-specific gSG5 family}

Transcripts coding for the gSG5 protein [114] were first discovered in the SGs of An. gambiae and shown to be exclusively expressed in the adult female SGs [13,115]. This protein produces weak similarity to a salivary protein of Ae aegypti [116] and better similarity to other Aedes [117] and Culex proteins [118], indicating this is a mosquito-specific protein. Six transcripts coding for this protein were found in the sialotranscriptome of An. darlingi. AD-196 is $46 \%$ identical to the An. gambiae orthologue and only $26 \%$ and $23 \%$ identical to the culicine proteins [119]. The function of this mosquito-specific protein remains unknown, but its tissue- and sex-specific expression profile suggests it is possibly related to blood feeding.

\section{Mosquito-specific gSG8 family}

The gSG8 is a highly divergent family, with members only from An. gambiae and Ae. aegypti [120]. Alignment of the three sequences displays a conserved motif L-C-W-A-X-K$\mathrm{x}(2)-P-T-A-x(6)-C-x(5)-K$, which might help identify new members of this family. In An. gambiae, this protein is spe- 
cifically expressed in female SGs [115], suggesting a likely role in blood feeding.

\section{Mosquito-specific basic tail family}

AD-216 and AD-217 represents two similar proteins deducted from two and three ESTs, respectively. They may represent splicing variants or alleles of the same gene [121]. The predicted mature peptides have $11.2 \mathrm{kDa}$ and solely match proteins found in other mosquito sialotranscriptomes or other hypothetical mosquito proteins [122]. The basic tail name derives from a conserved Lys-X$\mathrm{X}$-Lys or Lys-X-X-Arg found in the carboxyterminus of proteins derived from the genus Aedes but lacking in the anopheline sequences. The alignment indicates a conserved backbone and the absence of cysteine residues, from where the block pattern L-x-H-X-L-X-Y-L-X-D$x(17,18)-A-x(2)-Y-x(3)-A-x(3)-G$ can be deduced (Fig. 4A). The derived phylogram (Fig. 4B) follows the expected mosquito phylogeny. Ae. aegypti transcripts coding for the basic tail peptide were enriched in adult female SGs [7].

Mosquito-specific 4.3-kDa family

$\mathrm{AD}-476$ represents the peptide sequence of a mature protein of $4.1 \mathrm{kDa}$ having significant similarities only to other polypeptides found previously in culicine mosquito sialotranscriptomes or predicted proteomes of mosquitoes [123]. This is the first time a protein of this family is found in an anopheline sialotranscriptome. Alignment and phylogram of the mature predicted peptides shows that Ae. aegypti and C. quinquefasciatus have two such peptides, those of Anopheles matching the slightly smaller version (Fig. 5A). The derived phylogram indicates two clades grouping the short and the large forms. In $A e$. aegypti, transcripts coding for a member of this family were shown to be enriched in the adult female SGs [7].

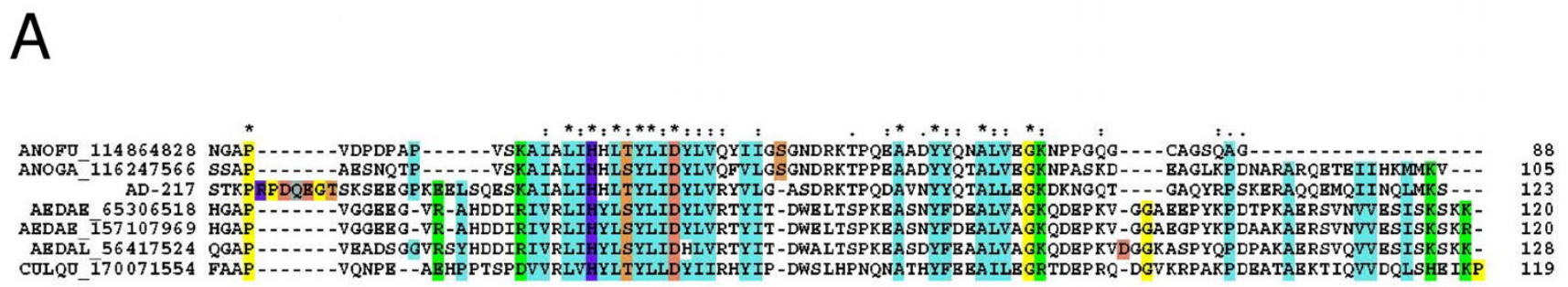

B

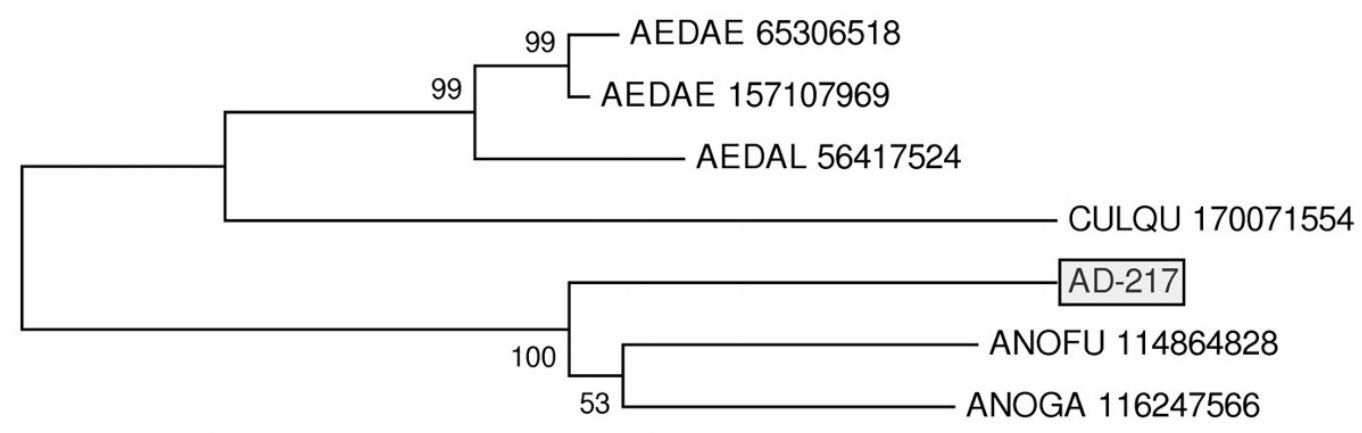

0.1

\section{Figure 4}

The salivary basic tail family of mosquito proteins. (A) Clustal alignment. The sole An. darlingi sequence is identified by AD-217. The remaining sequences are named with the first three letters from the genus name followed by two letters from the species name and by their NCBI protein accession number. Conserved cysteines are shown in black, hydrophobic conserved amino acids (aa) in light blue, conserved Pro and Gly in yellow, conserved bulky non-charged aa (Asn, Gln, Ser, Thr) in grey, conserved Ser + Thr in brown, conserved negatively charged aa in red, identical positively charged aa in violet, conserved charged aa in green. The symbols above the alignment indicate: $\left(^{*}\right)$ identical sites; (:) conserved sites; (.) less conserved sites. (B) Phylogram derived from the alignment in $(A)$. The numbers on the tree nodes represent the percent bootstrap support in 10,000 trials (only values above $50 \%$ are shown). The bar at the bottom indicates $10 \%$ aa divergence. 
A

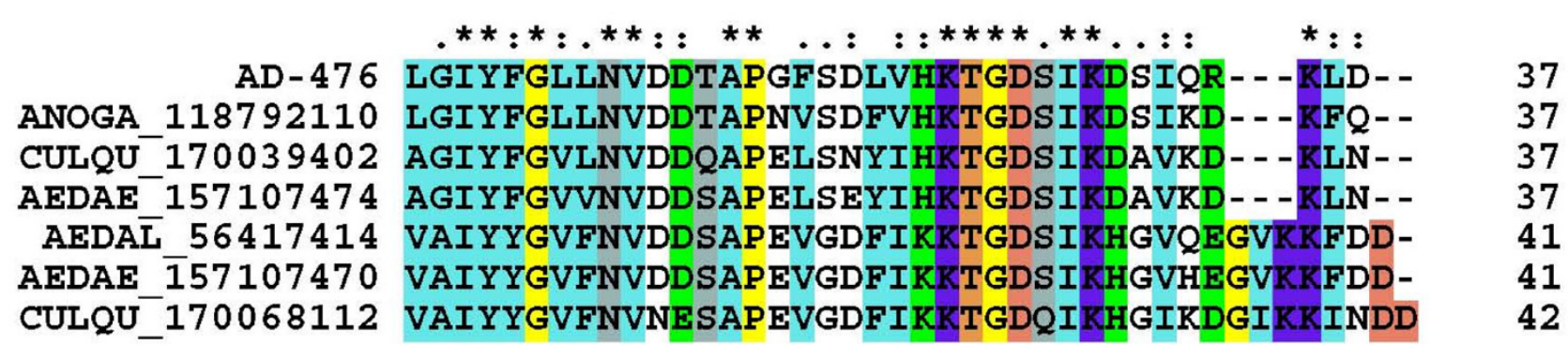

B

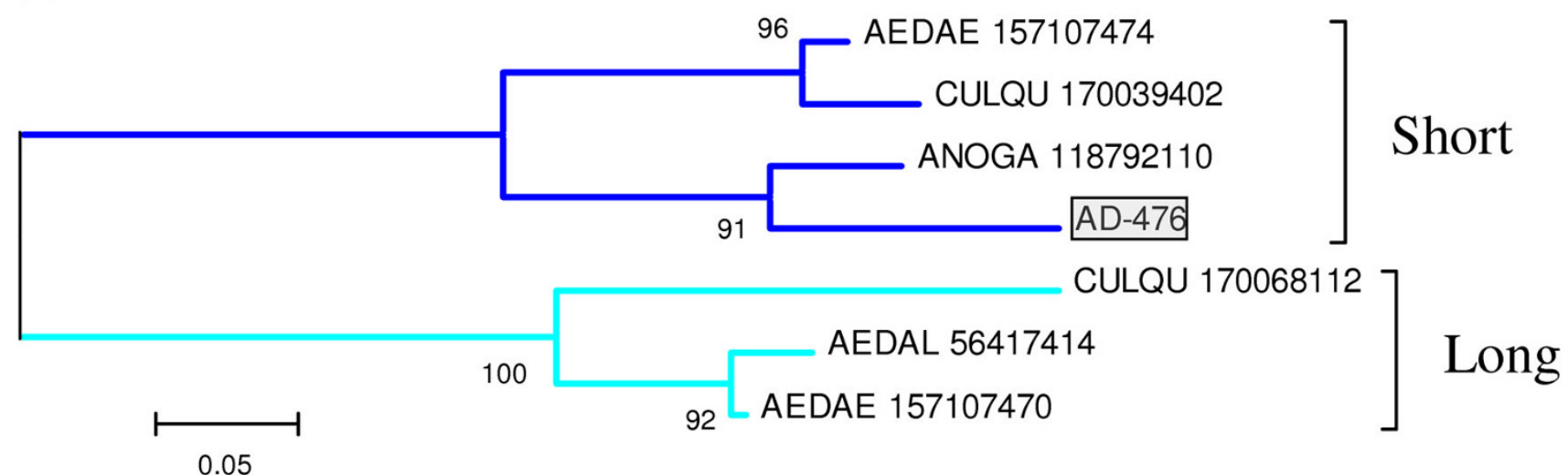

Figure 5

The salivary 4.3-kDa family of mosquito proteins. (A) Clustal alignment. The sole An. darlingi sequence is identified by AD-476. The remaining sequences are named with the first three letters from the genus name followed by two letters from the species name and by their NCBI protein accession number. Conserved cysteines are shown in black, hydrophobic conserved amino acids (aa) in light blue, conserved Pro and Gly in yellow, conserved bulky non-charged aa (Asn, Gln, Ser, Thr) in grey, conserved Ser + Thr in brown, identical negatively charged aa in red, identical positively charged aa in violet, conserved charged aa in green. The symbols above the alignment indicate: $(*)$ identical sites; (:) conserved sites; (.) less conserved sites. (B) Phylogram derived from the alignment in $(A)$. The numbers on the tree nodes represent the percent bootstrap support in 10,000 trials (only values above $50 \%$ are shown). The bar at the bottom indicates $5 \%$ aa divergence.

Culicine proline-rich secreted protein

The sialotranscriptome of Ae. aegypti identified a protein named proline-rich salivary secreted peptide [124], close homologues of which were never found in other sialotranscriptomes. Transcripts for this protein were found exclusively on the adult female SGs of Ae. aegypti, indicating a function related to acquisition of the blood meal [7]. The sialotranscriptome of An. darlingi provided three ESTs, which when assembled derive the sequence AD-267, matching this Aedes protein at $47 \%$ identity [125] and also, weakly, a smaller region of a salivary protein from An. stephensi of the same size. AD-267 was subjected to psiblast analysis against the NR database retrievieng only sequences from $A e$. aegypti, which converged after two iterations. The presence of AD-267 in An. darlingi, its homology to the Ae. aegypti protein, and its absence in An. gambiae suggest that the gene for this family existed in the ancestor of culicines and anophelines but was lost or modified beyond recognition in Culex and the Cellia subgenus of Anopheles.

\section{Culicine 4I.9-kDa family}

The first 41.9-kDa family member was characterized in sialotranscriptome of $A e$. aegypti and later found in $C$. quinquefasciatus and in Ae. albopictus $[4,7,8,10]$. It has never been found in any anopheline sialotranscriptome, nor does it have any similar protein predicted from the An. gambiae genome [126]. AD-114, however, produces similarities to $41.9-\mathrm{kDa}$ family members when subjected to blastp analysis against the NR database [127]. The blast results interestingly retrieves other salivary proteins from hematophagous Diptera from the NR database, such as 


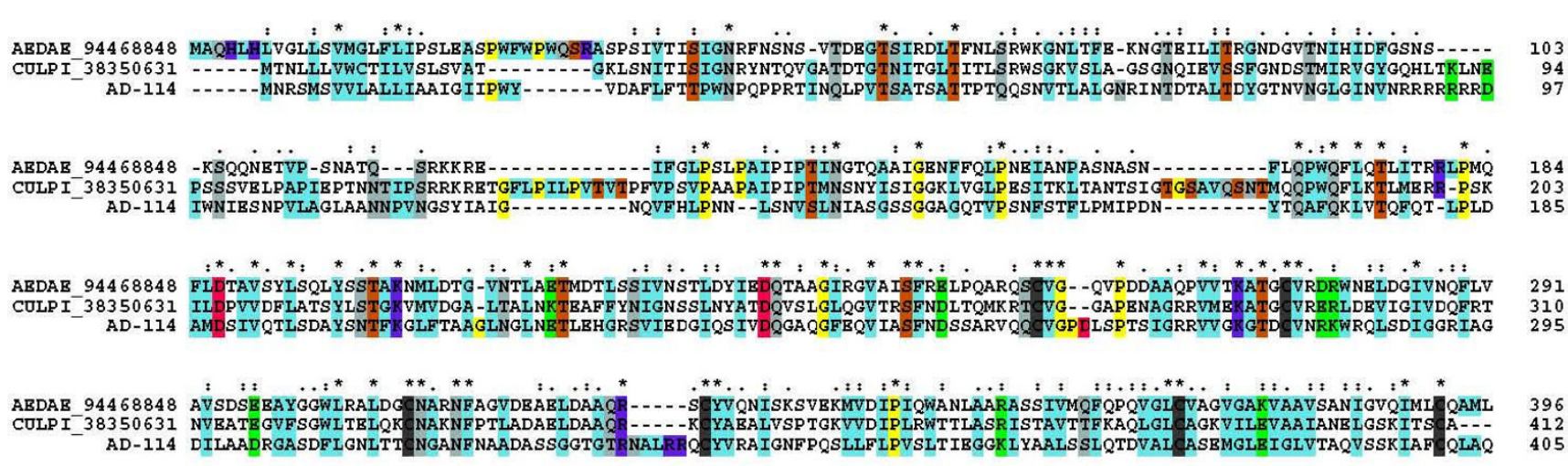

\section{Figure 6}

Clustal alignment of the 4I.9-kDa family of mosquito proteins. The sole An. darlingi sequence is identified by AD-I I4. The remaining sequences are named with the first three letters from the genus name followed by two letters from the species name and by their NCBI protein accession number. For more details, see text. Conserved cysteines are shown in black, hydrophobic conserved amino acids (aa) in light blue, conserved Pro and Gly in yellow, conserved bulky non-charged aa (Asn, Gln, Ser, Thr) in grey, conserved Ser + Thr in brown, conserved negatively charged aa in red, identical positively charged aa in violet, conserved charged aa in green. The symbols above the alignment indicate: $\left(^{*}\right)$ identical sites; (:) conserved sites; (.) less conserved sites.

gSG10, gSG9, and other mucins, despite having itself only three potential galactosylation sites. The alignment of the An. darlingi protein with the 41.9-kDa proteins from Ae. aegypti and C. quinquefasciatus shows extensive similarities over the whole length of the sequences, including a conserved cysteine framework, despite having less than 30\% identity with the culicine proteins (Fig. 6). AD-114 thus appear to be a "missing link" joining previously thought unrelated salivary protein families from Culicines and Anophelines. To further investigate this possibility, we used psiblast to search AD-114 against the NR database, retrieving mostly proteins found before in sialotranscriptomes of blood-sucking Diptera [128], including Culicoides $[49]$ and sand flies $[129,130]$. In addition to the known 41.9-kDa members from culicines, the anopheline proteins annotated as gSG10 and gSG9 are also retrieved, as are a group of proteins annotated as salivary mucins from mosquitoes, including the non-bloodfeeding species Toxorhynchites amboinensis [131]. Exceptionally, two bacterial proteins are retrieved, as well as one from the wasp Nasonia vitripennis. The alignment of the proteins from Diptera plus the two bacterial proteins by the Clustal tool does not reveal any region of common conservation among all proteins (not shown), but the derived bootstrapped phylogram (Fig. 7) is informative. Strong support is obtained for four clades, as indicated in Figure 7. The first clade includes sequences from both anopheline and culicine mosquitoes annotated as gSG10, gSG9, and mucins, together with the An. darlingi sequence. A second clade includes Culex and Aedes proteins annotated as mucins. This second clade roots with strong bootstrap support to the previous clade. A third clade includes Aedes proteins annotated as $41-\mathrm{kDa}$ protein, or a short version, annotated as $30.3-\mathrm{kDa}$ protein. This clade also roots strongly with the two previous clades. The sole C. quinquefasciatus sequence shown in Figure 7 (gi|170045863), the 41.9-kDa basic salivary protein, does not group significantly with any other sequence. Finally, a fourth clade groups together the bacterial and sand fly proteins. This clade does not root with strong bootstrap support to the previous clades. The presence of the bacterial proteins in this clade is puzzling, and suggests that the Nematocera proteins could have derived from bacterial contaminants. However, the proteins deriving from Ae. aegypti, C. quinquefasciatus and An. gambiae map to assembled chromosomes or supercontigs, and their respective genes contain introns indicating they are of eukaryotic origin. Together, these results support the argument that the 41.9-kDa protein family of mosquitoes has a common salivary ancestor before the split of anophelines and culicines, being recognized in An. darlingi by AD-114; in the Cellia subgenus, the 41.9-kDa protein family has evolved to produce shorter proteins, the subfamily members of the gSG10 and gSG9 families. Sand flies express related salivary proteins that might have been acquired by convergent evolution or share a distant common ancestor that can no longer be recognized with the available sequences.

\section{Anopheline-specific SGI family}

Six genes coding for proteins of this unique protein family were found in An. gambiae salivary transcriptomes $[11,12,115]$, four of which are located as a contiguous gene cluster [132] in chromosome X [13]. Remarkably, all these genes are uniexonic, unusual for eukaryotic genes 


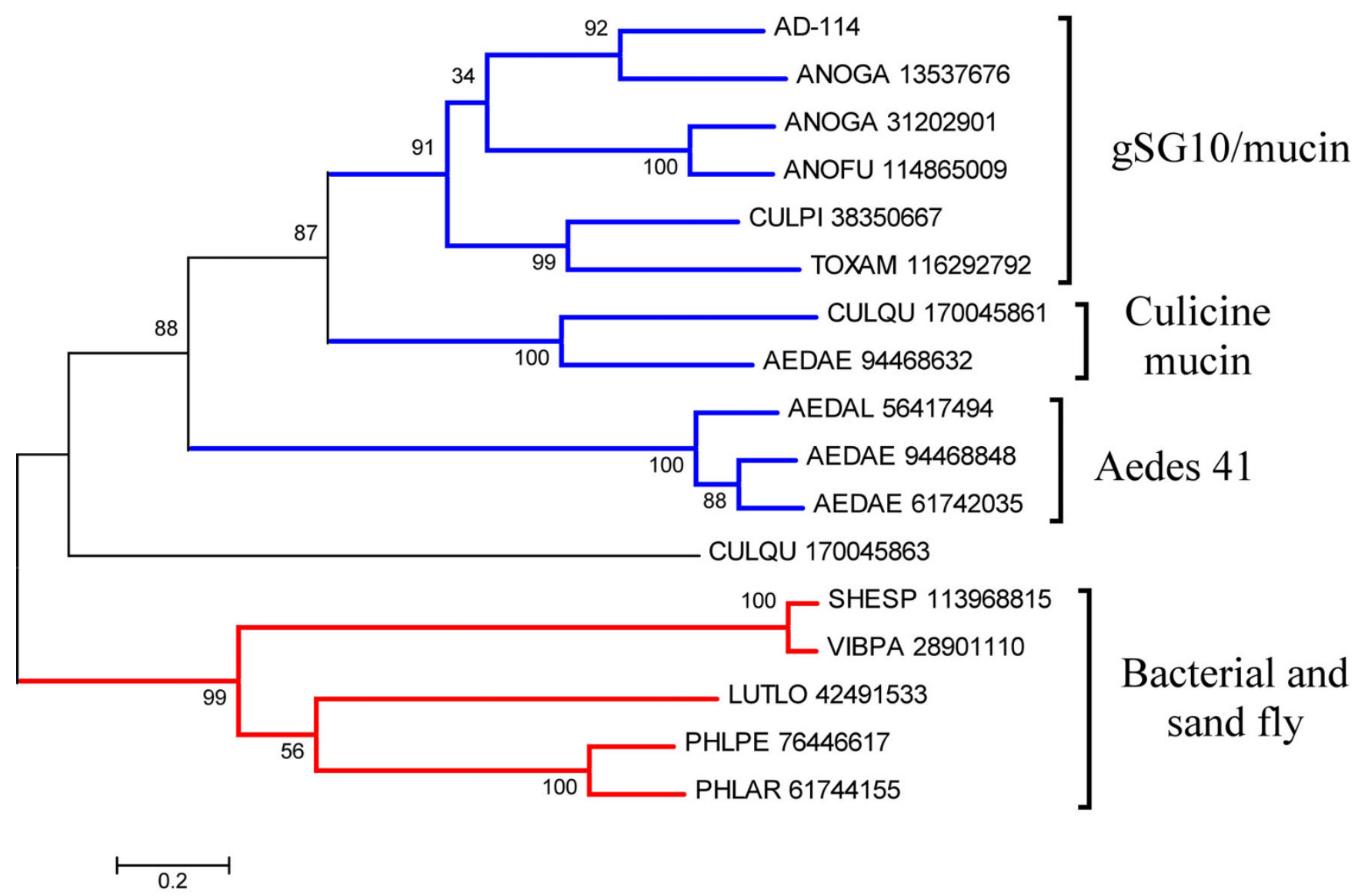

Figure 7

The expanded 4I.9-kDa family. Phylogram based on the alignment of sequences derived from the use of the PSI-BLAST tool to retrieve sequences on the NR database from the NCBI using as seed the An. darlingi sequence AD-I I4. The numbers on the tree nodes represent the percent bootstrap support in 10,000 trials (only values above $50 \%$ are shown). The bar at the bottom indicates $20 \%$ amino acid divergence. Except for the An. darlingi sequence, the remaining sequences are named with the first three letters from the genus name followed by two letters from the species name and by their NCBI protein accession number. For more details, see text.

coding for these relatively large proteins, attaining a mature molecular weight above $40 \mathrm{kDa}$, suggesting its acquisition as horizontal transfer. This gene family appears to be specifically associated with SG function. The transcripts coding for the Trio, SG1, and SG1b proteins appears to be exclusively expressed in the female SGs, while SG1-like3 and gSG1-2 and gSG1a are enriched in the female glands but also present in lower amounts in male glands and not observed in other tissues [13]. When these proteins were subjected to blastp against the NR database, only other anopheline sequences are retrieved. Sixty-three ESTs were found in the An. darlingi sialotranscriptome coding for proteins of this family, from which six full-length clones were sequenced. Of these six sequences, two possibly derive from alleles or splice variants [133]. When full-length protein sequences from all known members of this family are aligned by the Clustal tool, very few conserved aa are identified (Fig. 8A); how- ever, the deduced phylogram show strong bootstrap support for five clades (Fig. 8B), named for the An. gambiae proteins, as follows: Clade SG1/SG1a contains these two proteins from $A n$. gambiae and also one sequence each from An. stephensi, An. dirus, and An. darlingi. Clade SG1like3 contains two sequences from An. darlingi that could be the result of a recent gene duplication or polymorphism and splice variation [134]. These two sequences cluster with strong bootstrap support, as expected, with the sole sequence from An. albimanus. The Trio clade also has AD-153 from An. darlingi. The clade SG1-2 is the only clade not having An. darlingi representatives. The function of these proteins remains to be determined.

\section{Anopheline-specific SG2 family}

The SG2 protein was deduced from salivary An. gambiae cDNAs and shown to be expressed in female glands and adult males but not in other tissues [11]. It derives from a 
A
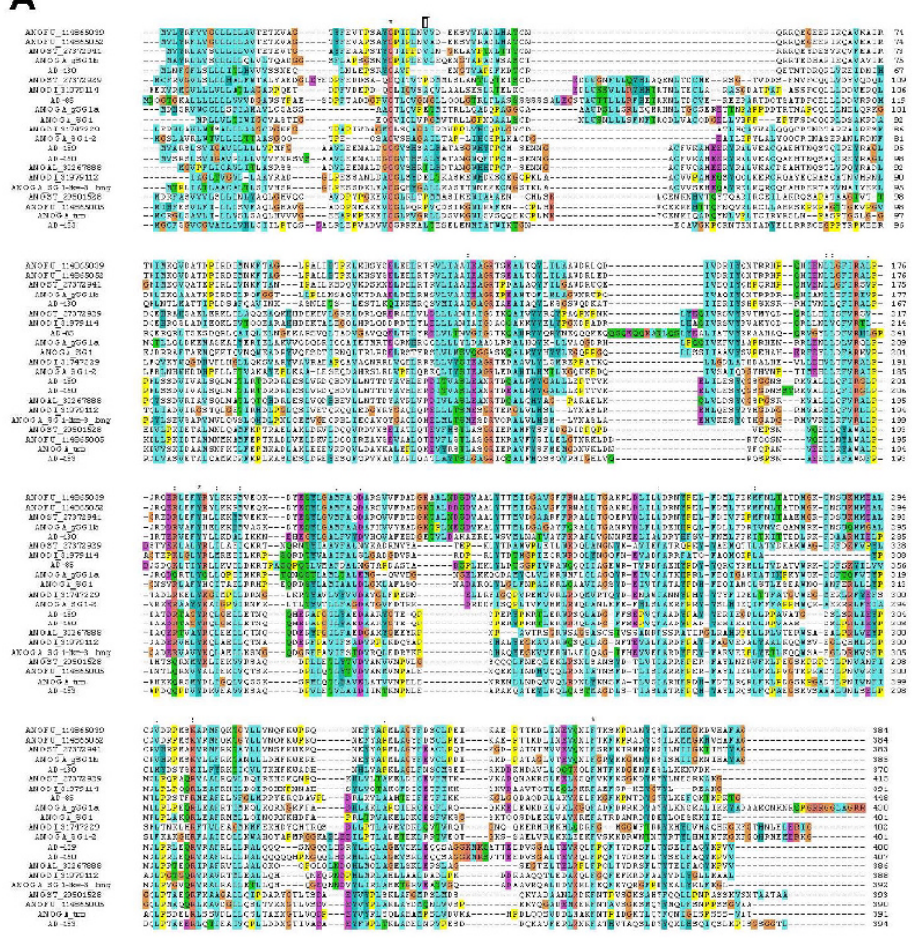

\section{B}

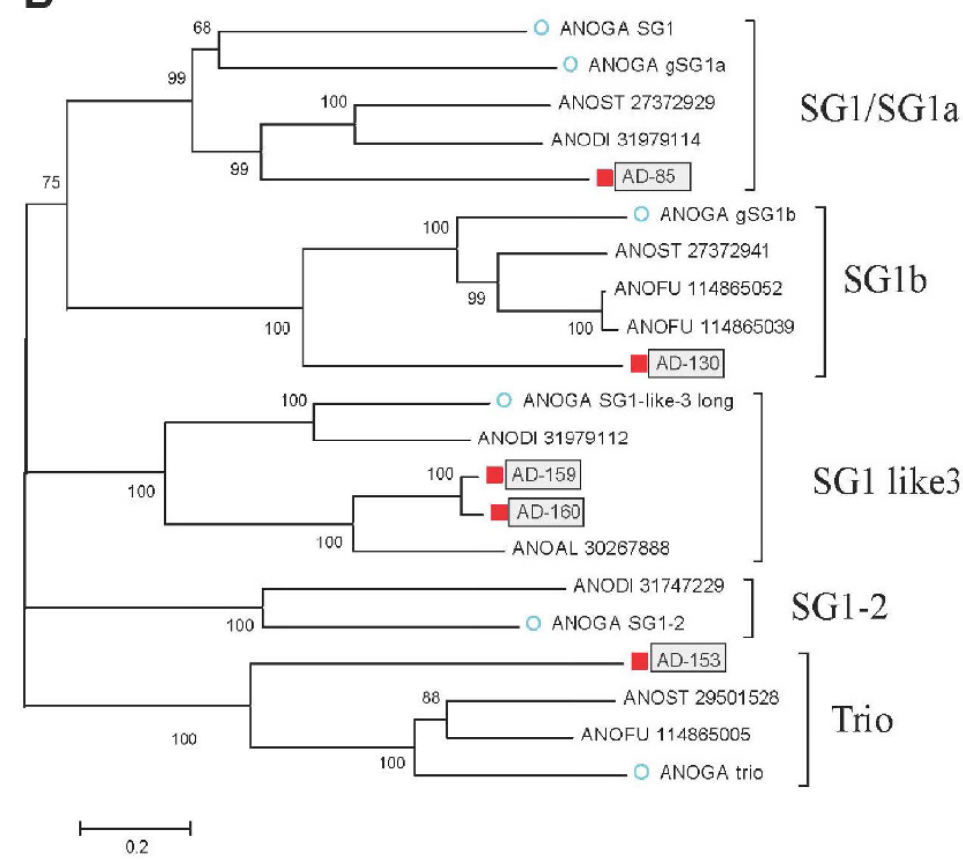

Figure 8

The GI protein family of anopheline mosquitoes. A) Clustal alignment. (B) Phylogram based on the alignment in (A). The numbers on the tree nodes represent the percent bootstrap support in 10,000 trials (only values above $50 \%$ are shown). The bar at the bottom indicates $20 \%$ amino acid divergence. The An. darlingi sequences are identified by AD and a filled square symbol. The An. gambiae sequences are identified by a circle and are named as reported before [7]. The remaining sequences are named with the first three letters from the genus name followed by two letters from the species name and by their $\mathrm{NCBI}$ protein accession number. For more details, see text. 
single gene in chromosome $2 \mathrm{~L}$ and is abundantly transcribed in sialotranscriptomes of male An. gambiae [135]. Related, but very divergent, sequences were obtained solely from salivary transcriptomes of other anopheline species [6]. The sialotranscriptome of An. darlingi indicates that at least two different genes exist coding for proteins of this family. One gene codes for mature proteins of $8.5 \mathrm{kDa}$, from which four alleles or splice variants are derived [136]. A second gene may have produced another five different alleles or splice variants coding for shorter (5.6- to 6.1-kDa) peptides [137], but it is more likely that these derive from two closely related genes. Comparison of these proteins with other anopheline sequences displays sequence identities varying from only $26 \%$ [138]to $31 \%$ [139]. Because this protein family is expressed in both male and female An. gambiae [11,135], and due to its relatively small size, it may display antimicrobial function.

\section{Anopheline-specific hyp 15/hyp 17 family}

The hyp 15 and hyp 17 proteins, previously identified in sialotranscriptomes of An. gambiae [12], have alkaline pI and $\sim 4.7 \mathrm{kDa}$. Their genes reside as tandem repeat in chromosome $\mathrm{X}$ and are preferentially expressed in adult female SGs [13]. Homologues were additionally found in An. stephensi and An. funestus. The An. darlingi sialotranscriptome presents evidence of three transcripts that may derive from splice variants from a single gene [140], which are $41 \%$ and $39 \%$ identical to the An. funestus and $A n$. gambiae homologue [141].

\section{Anopheline-specific hyp 8.2/hyp 6.2 family}

In An. gambiae, the genes coding for the hyp 8.2 and hyp 6.2 proteins are found as a tandem repeat in chromosome arm $2 \mathrm{~L}$. These proteins have mature molecular weight of 6-9 $\mathrm{kDa}$, do not have sequence similarity, and are grouped together solely by virtue of being chromosomal neighbours. Transcripts coding for these two polypeptides are similarly enriched in An. gambiae adult female SGs [13]. An. stephensi and An. funestus also have members of these protein families. In An. darlingi, two quite divergent protein sequences [142] deduced from the sialotranscriptome are similar to hyp 8.2 [143], and one is similar to hyp 6.2 [144].

\section{Anopheline-specific hyp 5.6 family}

An. darlingi protein AD-269 has a predicted molecular weight of $6.5 \mathrm{kDa}$ and matches [145] the carboxyterminus of a salivary peptide named hyp 5.6 previously described in An. gambiae sialotranscriptome [13]. Members of this family have not been found previously in other sialomes. In An. gambiae the transcript coding for hyp 5.6 was ubiquitously transcribed, suggesting a housekeeping or antimicrobial role.

\section{Anopheles 2 WIRRP salivary hypothetical protein}

A protein cryptically named hypothetical protein was previously identified in a cDNA library of An. gambiae [115], but homologues were never found in other sialotranscriptomes of either anopheline or culicine mosquitoes. This An. gambiae protein produces matches to other unrelated sequences in the NR database by virtue of repeated acidic amino acids. The sialotranscriptome of An. darlingi produced 60 transcripts matching this An. gambiae protein, distributed into six putative protein sequences deriving from possibly two genes [146], of which AD-18 represents a shorter form of the family (Fig. 9). The five remaining deduced sequences may result from alleles [147]. These

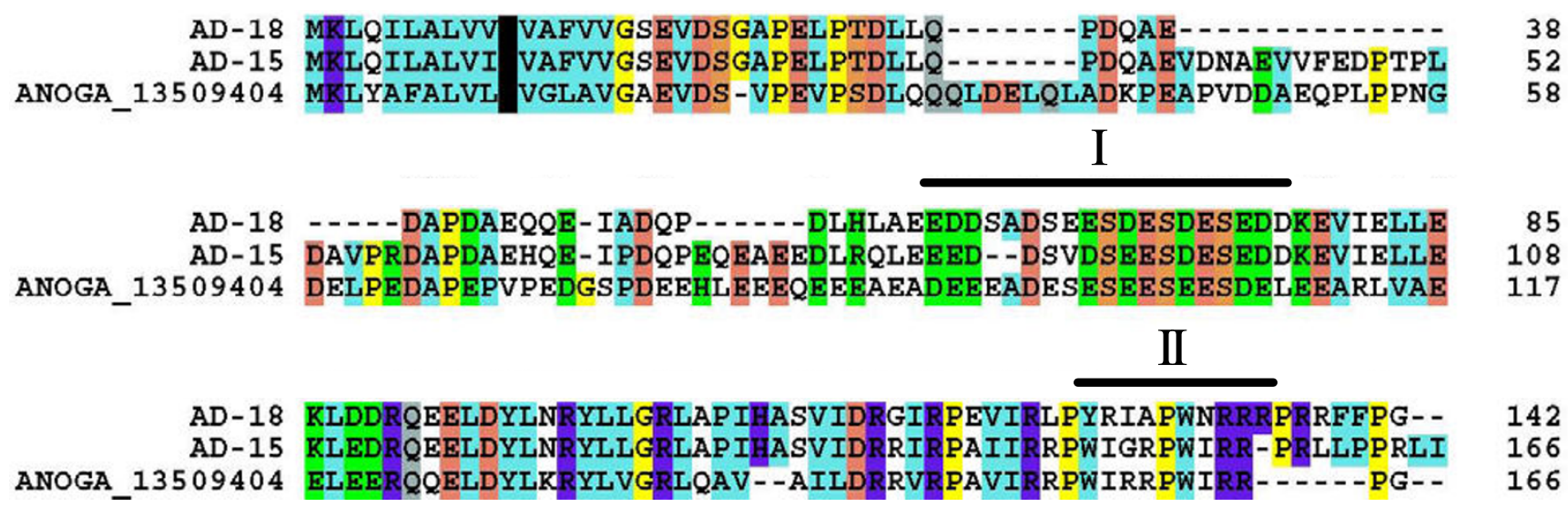

\section{Figure 9}

The 2WIRRP family of Anopheline proteins. Clustal alignment of the An. darlingi proteins with the An. gambiae homologue. Background colour follows convention as in Figure 6. Bar labelled I indicates region of Ser [Asp/Glu] [Asp-Glu] repeats. Bar labelled II identifies the WIRRP repeats notable on the An. gambiae sequence. 
proteins have predicted mature molecular weight of $14-$ $17 \mathrm{kDa}$ and pI of 4.2 . They are $41 \%$ [148] to $50 \%$ identical [149] to the An. gambiae homologue. Alignment of two of the An. darlingi sequences with the An. gambiae homologue identifies a region of Ser [Asp/Glu] [Asp-Glu] repeats (identified with a bar labelled I in Fig. 9) and a region of two repeats WIRRP in the An. gambiae sequence (identified with a bar labelled II in Fig. 9), which provides a name for the family.

\section{An. darlingi salivary-secreted orphan proteins}

Two An. darlingi protein sequences, never before evidenced in mosquito sialotranscriptomes, are described here with clear signal peptide indicative of a secretion. These are AD-136, which significantly matches only hypothetical proteins of An. gambiae, Ae. aegypti, and C. quinquefasciatus [150], and AD-119, which has no significant matches to any known protein in the NR database. Seven and 15 transcripts were found coding for each protein, respectively. AD-136 has an allele [151], AD-138, derived from two transcripts.

\section{An. darlingi salivary absentee proteins}

In a previous sialotranscriptome analysis of An. gambiae, 92 transcripts from a total of 4,066 [13] coded for a protein named gSG6 [115], orthologues of which were found in An. stephensi and An. funestus sialotranscriptomes [152]. Considering that we have sequenced in the present work 2,371 ESTs from An. darlingi, some 53 ESTs would have been expected for this protein. None were found, suggesting this family to be specific for the Cellia subgenus. Similarly, the related An. gambiae proteins named hyp 10 and hyp 12 [153] had 37 and 12 corresponding ESTs, but none were found in the An. darlingi cDNA library, also suggesting this family to be Cellia-specific.

\section{Comparison of protein sequence identities between An. darlingi and An. gambiae gene products}

Seventy-seven deduced protein sequences coding for putative housekeeping $(\mathrm{H})$ products are presented in Supplemental Table S2. These proteins allow comparison of the evolutionary rate of the $S$ proteins compared with that of the H proteins, using the An. gambiae proteome as a reference set as done before for comparing An. stephensi salivary proteins with those of An. gambiae [9]. For this comparison, we used only protein sequences from $A n$. darlingi that had at least 100 aa of alignment to an $A n$. gambiae protein, as identified by blastp with the filter for low complexity set to off. The protein identity in the two groups, $86 \%$ for the $\mathrm{H}$ and $53 \%$ for the $\mathrm{S}$ group, were significantly different $(P<0.001$, Mann-Whitney rank sum test) (Table 4), supporting the concept that the evolution of mosquito salivary-secreted proteins occurs at a faster pace than housekeeping proteins.

\section{Conclusion}

Anophelines diverged from culicine mosquitoes approximately 150 MYA [17]. Within anophelines, the new world species diverged from the old world forms concomitantly or before the breakup of Gondwanaland, at 95 MYA [154]. Within the anophelines, detailed sialotranscriptome analyses have been made only from members of the Cellia subgenus (An. gambiae, An. stephensi, and An. funestus). In addition, detailed sialotranscriptomes and proteome data are available for three culicines, Ae. aegypti, Ae. albopictus, and C. quinquefasciatus, and one mosquito of the subfamily Toxorhynchitinae, T. amboinensis. The insertion of a neotropical anopheline (subgenus Nyssorhyncus) fills a gap of information and helps to explain mosquito evolution with regard to adaptation to blood feeding through their salivary proteins.

From a conservative perspective, the sialotranscriptome of An. darlingi confirms the presence of ubiquitous salivary mosquito protein families, such as the $\mathrm{D} 7,30-\mathrm{kDa}$ antigen/aegyptin, mucins, AG5, gSG5, gSG8, basic tail, the enzymes apyrase $/ 5^{\prime}$ nucleotidase and amylase/maltase, and the immunity-related proteins lysozyme, defensin, cecropin, and Gly-His-rich peptides; most of these proteins are uniquely found in mosquitoes. From another standpoint, the An. darlingi sialotranscriptome has confirmed the presence of proteins so far known exclusively in anopheline mosquitoes, such as the antithrombin anophelin, the SG1, SG2, hyp 15/hyp 17, hyp 8.2/hyp 6.2, hyp 5.6, 2WIRRP. In the last two cases, the 2WIRRP and hyp 5.6, the An. darlingi sequences represent the second member of the family previously discovered in $A n$. gambiae but never before found in other anophelines.

Of interest, the An. darlingi sialotranscriptome also produced protein sequences with similarity to polypeptides previously found exclusively in culicine sialotranscriptomes, such as the proline-rich secreted protein, Kazal domain-containing peptides, and the 41.9-kDa family. Psiblast analysis of the An. darlingi sequence member of the 41.9-kDa family allowed identification of related Cellia anopheline sequences members previously known as gSG10 and gSG9, indicating these two families may have evolved quite rapidly from $41.9-\mathrm{kDa}$ ancestors that are now absent not only in the An. gambiae known sialotranscriptome, but also from any predicted protein from this mosquito genome (Fig. 7). On the other hand, An. darlingi lacks transcripts coding for proteins abundantly transcribed in An. gambiae and other Cellia mosquitoes, indicating the loss - or evolution beyond recognition - of these protein families in An. darlingi evolution.

Finally, the rapid divergence of salivary proteins allows the possibility of using such An. darlingi proteins as specific markers of vector exposure, as is now being 
Table 4: Identity at amino-acid level between Anopheles darlingi and An. gambiae salivary secreted and housekeeping proteins

\begin{tabular}{|c|c|c|c|}
\hline Secreted protein name & Name & Length & $\%$ identity \\
\hline$A D-32$ & Short D7r4 & 137 & 35 \\
\hline$A D-97$ & Short D7r4 & 130 & 29 \\
\hline AD-395 & Short D7r5 & 156 & 53 \\
\hline AD-I & Short D7r3 & 169 & 61 \\
\hline$A D-118$ & Long D7 I & 309 & 43 \\
\hline AD-23 & 30-kDa antigen & 252 & 59 \\
\hline AD- 133 & gSG7 anophensin & 134 & 47 \\
\hline AD-8 & SG3 mucin & 139 & 34 \\
\hline AD-I43 & gSGIO & 188 & 59 \\
\hline AD-47 & I3.5-kDa mucin & 149 & 34 \\
\hline AD- 104 & Apyrase & 571 & 66 \\
\hline AD-573 & Peroxidase & 592 & 86 \\
\hline$A D-38$ & gVAG & 261 & 67 \\
\hline$A D-430$ & Antigen 5 & 254 & 51 \\
\hline AD- 196 & gSG5 & 328 & 46 \\
\hline AD-217 & Basic tail & 116 & 48 \\
\hline AD- 159 & SGI-like3 & 376 & 33 \\
\hline$A D-130$ & gSGIb & 351 & 35 \\
\hline AD-86 & SGI & 409 & 30 \\
\hline AD- 153 & Trio & 383 & 29 \\
\hline AD- 138 & Unknown secreted & 241 & 60 \\
\hline AD-191 & Virus-induced mucin & 277 & 71 \\
\hline AD-457 & Peptidoglycan recognition protein & 188 & 94 \\
\hline AD- 174 & Lysozyme & 138 & 80 \\
\hline AD-70 & Maltase & 567 & 80 \\
\hline Mean & & 272.6 & 53.2 \\
\hline SE & & 29.0 & 3.8 \\
\hline SD & & 144.9 & 19.1 \\
\hline
\end{tabular}

\begin{tabular}{|c|c|c|c|}
\hline Housekeeping protein name & Name & Length & $\%$ identity \\
\hline$A D-519$ & Tetraspanin & 249 & 85 \\
\hline$A D-680$ & Unknown conserved & 188 & 90 \\
\hline AD-408 & Tetraspanin & 288 & 74 \\
\hline AD- 184 & Unknown conserved & 144 & 86 \\
\hline AD-527 & Unknown conserved & 101 & 87 \\
\hline AD-77 & Unknown conserved & 137 & 45 \\
\hline AD-79 & Unknown conserved & 137 & 45 \\
\hline$A D-401$ & Unknown conserved & 270 & 56 \\
\hline AD-584 & Ferritin & 231 & 65 \\
\hline AD-94 & Conserved secreted protein & 104 & 84 \\
\hline AD-345 & Conserved secreted protein & 126 & 92 \\
\hline$A D-640$ & Conserved secreted protein & 126 & 90 \\
\hline AD- 189 & Conserved secreted protein & 119 & 79 \\
\hline AD-939 & Conserved secreted protein & 136 & 30 \\
\hline AD-870 & $\mathrm{N}$-methyl-D-aspartate receptor-associated protein & 100 & 87 \\
\hline AD-489 & Phosphatidic acid phosphatase & 298 & 66 \\
\hline AD-205 & 40S ribosomal protein SA (P40)/Laminin receptor I & 290 & 82 \\
\hline AD- 195 & Ribosomal protein S4 & 262 & 91 \\
\hline AD-220 & $60 S$ ribosomal protein $L 7$ & 258 & 84 \\
\hline AD-398 & Similar to 3-hydroxybutyrate dehydrogenase type 2 & 255 & 90 \\
\hline AD- 165 & $60 S$ ribosomal protein L7A - truncated at 5 prime & 253 & 80 \\
\hline AD-224 & 60 s ribosomal protein $\mathrm{L} 2 / \mathrm{L} 8$ & 252 & 96 \\
\hline AD- 167 & $40 \mathrm{~S}$ ribosomal protein $\mathrm{S} 3 \mathrm{~A}$ & 247 & 93 \\
\hline AD-295 & emp24/gp25L/p24 family of membrane trafficking protein & 211 & 92 \\
\hline AD-328 & Peptidyl-prolyl cis-trans isomerase & 202 & 89 \\
\hline AD-207 & Ribosomal protein L19 & 190 & 95 \\
\hline AD-225 & 605 ribosomal protein $\mathrm{L} 9$ & 190 & 88 \\
\hline
\end{tabular}


Table 4: Identity at amino-acid level between Anopheles darlingi and An. gambiae salivary secreted and housekeeping proteins (Continued)

\begin{tabular}{|c|c|c|c|}
\hline AD-20I & 60s ribosomal protein LI8 & 189 & 86 \\
\hline AD-193 & $60 \mathrm{~S}$ ribosomal protein LII & 188 & 93 \\
\hline AD-222 & $60 S$ ribosomal protein $\mathrm{L} 22$ & 187 & 95 \\
\hline AD-7IO & Nucleoside diphosphate kinase & 168 & 93 \\
\hline AD-246 & $60 S$ ribosomal protein L2I & 162 & 83 \\
\hline$A D-126$ & $40 S$ ribosomal protein $\mathrm{S} 19$ & 157 & 88 \\
\hline$A D-156$ & Ribosomal protein L22 & 154 & 84 \\
\hline$A D-180$ & 60 S ribosomal protein $\mathrm{LI} 3 \mathrm{~A}$ & 154 & 79 \\
\hline AD-212 & 40S ribosomal protein SII & 153 & 92 \\
\hline$A D-215$ & 60 s ribosomal protein L24 & 153 & 89 \\
\hline AD-25I & $40 \mathrm{~S}$ ribosomal protein $\mathrm{SI} 4$ & 152 & 99 \\
\hline AD-253 & $60 S$ ribosomal protein L26 & $|5|$ & 94 \\
\hline AD-937 & Hypothetical conserved protein & 150 & 92 \\
\hline AD-235 & $40 \mathrm{~S}$ ribosomal protein $\mathrm{SI} 5$ & 149 & 94 \\
\hline$A D-|5|$ & Ribosomal protein SI6 & 146 & 96 \\
\hline AD-24I & 60 S ribosomal protein LI4/LI7/L23 & 140 & 100 \\
\hline AD-252 & $40 \mathrm{~S}$ ribosomal protein $\mathrm{S} 12$ & 136 & 97 \\
\hline AD-28I & $\mathrm{H} 3$ histone, family $3 \mathrm{~A}$ & 136 & 99 \\
\hline AD-245 & Ribosomal protein L32 & 134 & 93 \\
\hline AD-592 & Mitochondrial ribosomal protein L54 & 134 & 83 \\
\hline AD-230 & $40 \mathrm{~S}$ ribosomal protein $\mathrm{SI}$ & $|3|$ & 98 \\
\hline AD-239 & Ubiquitin-like/40S ribosomal S30 protein fusion & $|3|$ & 76 \\
\hline AD-240 & $40 \mathrm{~S}$ ribosomal protein $\mathrm{SI} 5 / \mathrm{S} 22$ & 130 & 97 \\
\hline AD-229 & Ubiquitin/60s ribosomal protein L40 fusion & 128 & 100 \\
\hline AD-242 & Ribosomal protein S8 & 126 & 84 \\
\hline AD-280 & $\mathrm{H} 2 \mathrm{~A}$ histone family, member $\mathrm{V}$ & 126 & 95 \\
\hline AD-250 & $60 S$ ribosomal protein $\mathrm{L} 3 \mathrm{I}$ & 124 & 99 \\
\hline AD-185 & $40 S$ ribosomal protein $\mathrm{S} 20$ & 120 & 92 \\
\hline$A D-117$ & Acidic ribosomal protein $\mathrm{PI}$ & 115 & 89 \\
\hline AD-247 & $60 S$ ribosomal protein $\mathrm{L} 36$ & 113 & 95 \\
\hline AD-120 & $60 S$ acidic ribosomal protein $\mathrm{P} 2$ & 113 & 82 \\
\hline AD-262 & Mitochondrial FIFO-ATP synthase, subunit Cf6 & 107 & 90 \\
\hline AD-116 & Translation elongation factor $\mathrm{EF}-\mathrm{I}$ alpha/Tu & 103 & 97 \\
\hline Mean & & 167.1 & 86.1 \\
\hline SE & & 7.1 & 1.8 \\
\hline SD & & 55.0 & 13.8 \\
\hline
\end{tabular}

attempted for An. gambiae and Ae. aegypti [155-158]. Additionally, to the extent that the rapid divergence of the salivary proteins is not associated with divergence of function, the differences between orthologous salivary proteins between An. gambiae and An darlingi, and also among anophelines of the different subfamilies, represents a natural site-directed mutagenesis experiment that will help identify structural determinants of function in such bioactive proteins [159-161].

\section{Methods}

\section{Mosquitoes and cDNA library construction}

The sequences utilized in this study originated from the same cDNA library used in our previous publication [5]. This cDNA library was derived from SGs dissected from adult female An. darlingi of unknown ages that were field caught in Porto Velho, Rondonia, Brazil. PolyA ${ }^{+}$RNA was extracted from 60 dissected pairs of SGs using the MicroFastTrack mRNA isolation kit (Invitrogen), which was then used to make a PCR-based cDNA library using the
SMART $^{\mathrm{TM}}$ cDNA library construction kit (BD BiosciencesClontech) as described before [10].

\section{cDNA sequencing}

The SG cDNA library was plated on $\mathrm{LB} / \mathrm{MgSO}_{4}$ plates containing X gal/IPTG to an average of 250 plaques per 150 $\mathrm{mm}$ Petri plate. Recombinant (white) plaques were randomly selected and transferred to 96-well Microtest ${ }^{\mathrm{TM}} \mathrm{U}$ bottom plates (BD BioSciences) containing $100 \mu \mathrm{l}$ of SM buffer $\left(0.1 \mathrm{M} \mathrm{NaCl} ; 0.01 \mathrm{M} \mathrm{MgSO}_{4} ; 7 \mathrm{H}_{2} \mathrm{O} ; 0.035 \mathrm{M}\right.$ Tris $\mathrm{HCl}[\mathrm{pH} 7.5] ; 0.01 \%$ gelatin) per well. The plates were covered and placed on a gyrating shaker for $30 \mathrm{~min}$ at room temperature. The phage suspension was either immediately used for PCR or stored at $4{ }^{\circ} \mathrm{C}$ for future use.

To amplify the cDNA using a PCR reaction, $4 \mu \mathrm{l}$ of the phage sample was used as a template. The primers were sequences from the $\lambda$ TriplEx2 vector and named pTEx2 5 seq ( 5 ' TCC GAG ATC TGG ACG AGC 3') and pTEx2 3LD (5' ATA CGA CTC ACT ATA GGG CGA ATT GGC 3'), posi- 
tioned at the 5 ' end and the $3^{\prime}$ end of the cDNA insert, respectively. The reaction was carried out in 96-well flexible PCR plates (Applied Biosystems) using FastStart Taq polymerase (Roche) on a GeneAmp ${ }^{\circledR}$ PCR system 9700 (Perkin Elmer Corp.). The PCR conditions were: one hold of $95^{\circ} \mathrm{C}$ for $3 \mathrm{~min} ; 25$ cycles of $95^{\circ} \mathrm{C}$ for $1 \mathrm{~min}, 61^{\circ} \mathrm{C}$ for $30 \mathrm{sec} ; 72^{\circ} \mathrm{C}$ for $5 \mathrm{~min}$. The amplified products were analysed on a $1.5 \%$ agarose/EtBr gel. cDNA library clones were PCR amplified, and those showing a single band were selected for sequencing. Approximately 200-250 ng of each PCR product was transferred to ThermoFast 96well PCR plates (ABgene Corp.) and frozen at $-20^{\circ} \mathrm{C}$ before cycle sequencing using an ABI3730XL machine. The obtained sequences were submitted to DBEST and have the GenBank accession numbers FK703778FK705605.

\section{Primer extension experiments on selected clones}

These were performed using sequencing primers designed by the Primer3 program [162], aimed at a region $~ 100 \mathrm{bp}$ upstream (5') of the end of the previously obtained sequence information of high quality. The process was repeated until full length information was obtained. The primer extension sequences were submitted to DBEST and have the accession numbers FL688077-FL688134. The sequences representing the open reading frames shown in supplemental table 2 have been deposited to GenBank and have the accession numbers EU934251-EU934432.

\section{Bioinformatic tools and procedures}

ESTs were trimmed of primer and vector sequences. The BLAST suite of programs [18], CAP3 assembler [163] and ClustalW [164] software were used to compare, assemble, and align sequences, respectively. Phylogenetic analysis and statistical neighbour-joining (NJ) bootstrap tests of the phylogenies were done with the Mega package [165]. For functional annotation of the transcripts we used blastx [18] to compare the nucleotide sequences with the NR protein database of the NCBI and to the Gene Ontology (GO) database [19]. The program reverse position-specific BLAST (RPS-BLAST) [18] was used to search for conserved protein domains in the Pfam [166], SMART [167], Kog [168], and conserved domains databases (CDD) [20]. We have also compared the transcripts with other subsets of mitochondrial and rRNA nucleotide sequences downloaded from NCBI and to several organism proteomes downloaded from NCBI, ENSEMBL, or VectorBase. Segments of the three-frame translations of the EST (because the libraries were unidirectional, six-frame translations were not used) starting with a methionine found in the first 300 predicted aa, or the predicted protein translation in the case of complete coding sequences, were submitted to the SignalP server [169] to help identify translation products that could be secreted. O-glycosylation sites on the proteins were predicted with the program NetOGlyc
[170]. Functional annotation of the transcripts was based on all the comparisons above. Following inspection of all these results, transcripts were classified as either secretory (S), housekeeping ( $\mathrm{H}$ ) or of unknown (U) function, with further subdivisions based on function and/or protein families.

\section{Abbreviations}

aa: amino acid; AMP: antimicrobial peptide; AG5: antigen 5 family; EST: expressed sequence tag; H class: housekeeping; NR: nonredundant; OBP: odorant-binding protein; S class: secreted; SG: salivary gland; SMART: switching mechanism at 5 ' end of RNA transcript; U class: unknown function.

\section{Authors' contributions}

EC and JFA helped with library manufacture, sequencing, data analysis, and contributed to the manuscript. VMP participated in sequencing the NIH library. OM helped with experiment design and contributed to manuscript. JMCR performed data analysis and contributed to the manuscript. All authors read and approved the final manuscript.

\section{Additional material}

\section{Additional file 1 \\ Assembled and annotated sialotranscriptome of An. darlingi female mosquitoes. Hyperlinked Excel spreadsheet and associated files with EST assembly results. This is a compressed ZIP file that should be expanded to a new directory. After this is done, start Excel and then open the file end- ing in .xls so the hyperlinks will work. \\ Click here for file \\ [http://www.biomedcentral.com/content/supplementary/1471- 2164-10-57-S1.zip] \\ Additional file 2 \\ Annotated sialotranscriptome of An. darlingi female mosquitoes. Hyperlinked Excel spreadsheet with deducted protein sequences. See description above. \\ Click here for file \\ [http://www.biomedcentral.com/content/supplementary/1471- 2164-10-57-S2.zip]}

\section{Acknowledgements}

This work was supported by the Intramural Research Program of the Division of Intramural Research, National Institute of Allergy and Infectious Diseases, National Institutes of Health. We thank Dr. Bruno Arcà for valuable discussions, and NIAID intramural editor Brenda Rae Marshall for assistance.

Because EC, VMP, JFA, and JMCR are government employees and this is a government work, the work is in the public domain in the United States. Notwithstanding any other agreements, the NIH reserves the right to provide the work to PubMedCentral for display and use by the public, and PubMedCentral may tag or modify the work consistent with its customary 
practices. You can establish rights outside of the U.S. subject to a government use license.

\section{References}

I. Ribeiro JMC: Blood-feeding arthropods: Live syringes or invertebrate pharmacologists? Infect Agents Dis 1995, 4:|43-I52.

2. Ribeiro JM, Francischetti IM: Role of arthropod saliva in blood feeding: sialome and post-sialome perspectives. Annu Rev Entomol 2003, 48:73-88.

3. Marinotti $O$, James $A A$ : An alpha-glucosidase in the salivary glands of the vector mosquito, Aedes aegypti. Insect Biochem 1990, 20:619-623.

4. Arca B, Lombardo F, Francischetti IM, Pham VM, Mestres-Simon M, Andersen JF, Ribeiro JM: An insight into the sialome of the adult female mosquito Aedes albopictus. Insect Biochem Mol Biol 2007 37:107-127.

5. Calvo E, Andersen J, Francischetti IM, de LCM, deBianchi AG, James AA, Ribeiro JM, Marinotti O: The transcriptome of adult female Anopheles darlingi salivary glands. Insect Mol Biol 2004, I 3:73-88.

6. Calvo E, Dao A, Pham VM, Ribeiro JM: An insight into the sialome of Anopheles funestus reveals an emerging pattern in anopheline salivary protein families. Insect Biochem Mol Biol 2007, 37:164-175.

7. Ribeiro JM, Arca B, Lombardo F, Calvo E, Phan VM, Chandra PK, Wikel SK: An annotated catalogue of salivary gland transcripts in the adult female mosquito, Aedes aegypti. BMC Genomics 2007, 8:6.

8. Ribeiro JM, Charlab R, Pham VM, Garfield M, Valenzuela JG: An insight into the salivary transcriptome and proteome of the adult female mosquito Culex pipiens quinquefasciatus. Insect Biochem Mol Biol 2004, 34:543-563.

9. Valenzuela JG, Francischetti IM, Pham VM, Garfield MK, Ribeiro JM: Exploring the salivary gland transcriptome and proteome of the Anopheles stephensi mosquito. Insect Biochem Mol Biol 2003, 33:717-732.

10. Valenzuela JG, Pham VM, Garfield MK, Francischetti IM, Ribeiro JMC Toward a description of the sialome of the adult female mosquito Aedes aegypti. Insect Biochem Mol Biol 2002, 32: I I 1 I-I I 22.

11. Arca B, Lombardo F, de Lara Capurro M, della Torre A, Dimopoulos $G$, James AA, Coluzzi M: Trapping cDNAs encoding secreted proteins from the salivary glands of the malaria vector Anopheles gambiae. Proc Natl Acad Sci USA 1999, 96:1516-1521.

12. Francischetti IM, Valenzuela JG, Pham VM, Garfield MK, Ribeiro JM Toward a catalog for the transcripts and proteins (sialome) from the salivary gland of the malaria vector Anopheles gambiae. J Exp Biol 2002, 205:2429-245I.

13. Arca B, Lombardo F, Valenzuela JG, Francischetti IM, Marinotti O Coluzzi M, Ribeiro JM: An updated catalogue of salivary gland transcripts in the adult female mosquito, Anopheles gambiae. J Exp Biol 2005, 208:397|-3986.

14. Zimmerman RH: Ecology of malaria vectors in the Americas and future direction. Mem Inst Oswaldo Cruz 1992, 87(Suppl 3):37I-383.

15. Moreira-Ferro CK, Daffre S, James AA, Marinotti O: A lysozyme in the salivary glands of the malaria vector Anopheles darlingi. Insect Mol Biol 1998, 7:257-264.

16. Calvo $E$, deBianchi AG, James AA, Marinotti $O$ : The major acid soluble proteins of adult female Anopheles darlingi salivary glands include a member of the D7-related family of proteins. Insect Biochem Mol Biol 2002, 32:|4| 9-|427.

17. Krzywinski J, Grushko OG, Besansky NJ: Analysis of the complete mitochondrial DNA from Anopheles funestus: an improved dipteran mitochondrial genome annotation and a temporal dimension of mosquito evolution. Mol Phylogenet Evol 2006, 39:417-423.

18. Altschul SF, Madden TL, Schaffer AA, Zhang J, Zhang Z, Miller W, Lipman DJ: Gapped BLAST and PSI-BLAST: a new generation of protein database search programs. Nucleic Acids Res 1997, 25:3389-3402

19. Ashburner M, Ball CA, Blake JA, Botstein D, Butler H, Cherry JM, Davis AP, Dolinski K, Dwight SS, Eppig JT, Harris MA, Hill DP, IsselTarver L, Kasarskis A, Lewis S, Matese JC, Richardson JE, Ringwald M, Rubin GM, Sherlock G: Gene ontology: tool for the unification of biology. The Gene Ontology Consortium. Nat Genet 2000, 25:25-29.
20. Marchler-Bauer A, Panchenko AR, Shoemaker BA, Thiessen PA, Geer LY, Bryant SH: CDD: a database of conserved domain alignments with links to domain three-dimensional structure. Nucleic Acids Res 2002, 30:281-283.

21. Galperin MY, Koonin EV: 'Conserved hypothetical' proteins: prioritization of targets for experimental study. Nucleic Acids Res 2004, 32:5452-5463.

22. James AA, Blackmer K, Marinotti O, Ghosn CR, Racioppi JV: Isolation and characterization of the gene expressing the major salivary gland protein of the female mosquito, Aedes aegypti. Mol Biochem Parasitol I991, 44:245-254.

23. Arca B, Lombardo F, Lanfrancotti A, Spanos L, Veneri M, Louis C Coluzzi M: A cluster of four D7-related genes is expressed in the salivary glands of the African malaria vector Anopheles gambiae. Insect Mol Biol 2002, I I:47-55.

24. Valenzuela JG, Charlab R, Gonzalez EC, Miranda-Santos IKF, Marinotti O, Francischetti IM, Ribeiro JMC: The D7 family of salivary proteins in blood sucking Diptera. Insect Mol Biol 2002 I I: | 49- I 55

25. Hekmat-Scafe DS, Dorit RL, Carlson JR: Molecular evolution of odorant-binding protein genes OS-E and OS-F in Drosophila. Genetics 2000, I55: I I7-I 27.

26. Calvo E, Mans BJ, Andersen JF, Ribeiro JM: Function and evolution of a mosquito salivary protein family. J Biol Chem 2006, 281:1935-1942.

27. Mans BJ, Calvo E, Ribeiro JM, Andersen JF: The crystal structure of D7r4, a salivary biogenic amine-binding protein from the malaria mosquito Anopheles gambiae. J Biol Chem 2007, 282:36626-36633.

28. Isawa $H$, Yuda $M$, Orito $Y$, Chinzei $Y$ : A mosquito salivary protein inhibits activation of the plasma contact system by binding to factor XII and high molecular weight kininogen. J Biol Chem 2002, 277(3I):2765I-27658.

29. An. darlingi D7 sequences [http://exon.niaid.nih.gov/transcrip tome/A darlingi/T2/links/TICK-BLOCKS/AD-I-TICK-BLOCKS.txt]

30. Simons FE, Peng Z: Mosquito allergy: recombinant mosquito salivary antigens for new diagnostic tests. Int Arch Allergy Immunol 200 I, I 24:403-405

31. Jariyapan N, Choochote W, Jitpakdi A, Harnnoi T, Siriyasatein P, Wilkinson MC, Bates PA: A glycine- and glutamate-rich protein is female salivary gland-specific and abundant in the malaria vector Anopheles dirus B (Diptera: Culicidae). I Med Entomol 2006, 43:867-874.

32. Cazares-Raga FE, Gonzalez-Lazaro M, Montero-Solis C, GonzalezCeron L, Zamudio F, Martinez-Barnetche J. Torres-Monzon JA Ovilla-Munoz M, Aguilar-Fuentes J, Rodriguez $\mathrm{MH}$, de la Cruz Hernandez-Hernandez F: GP35 ANOAL, an abundant acidic glycoprotein of female Anopheles albimanus saliva. Insect $\mathrm{Mol} B i o l$ 2007, 16:187-198.

33. Yoshida $\mathrm{S}$, Watanabe $\mathrm{H}$ : Robust salivary gland-specific transgene expression in Anopheles stephensi mosquito. Insect Mol Biol 2006, I 5:403-4I0.

34. Calvo E, Tokumasu F, Marinotti O, Villeval JL, Ribeiro JM, Francischetti IM: Aegyptin, a novel mosquito salivary gland protein, specifically binds to collagen and prevents its interaction with platelet glycoprotein VI, integrin alpha2betal, and von Willebrand factor. J Biol Chem 2007, 282:26928-26938.

35. Yoshida S, Sudo T, Niimi M, Tao L, Sun B, Kambayashi J, Watanabe H, Luo $\mathrm{E}$, Matsuoka $\mathrm{H}$ : Inhibition of collagen-induced platelet aggregation by anopheline antiplatelet protein, a saliva protein from a malaria vector mosquito. Blood 2008 , I I I:2007-20|4.

36. An. darlingi Aegyptins [http://exon.niaid.nih.gov/transcriptome/ A darlingi/T2/links/cluster/anda-tb295-50-Sim-CLTLI.txt]

37. Weskamp G, Blobel CP: A family of cellular proteins related to snake venom disintegrins. Proc Natl Acad Sci USA 1994, 9l:2748-275I.

38. Mans BJ, Louw Al, Neitz AW: Savignygrin, a platelet aggregation inhibitor from the soft tick Ornithodoros savignyi, presents the RGD integrin recognition motif on the Kunitz-BPTI fold. J Biol Chem 2002, 277:2 I37|-21378.

39. Niewiraowski S, McLane MA, Kloczewiak M, Stewart GJ: Disintegrins and other naturally occurring antagonists of platelet fibrinogen receptors. Semin Hematol 1994, 3 I (4):289-300.

40. Valenzuela JG, Francischetti IM, Ribeiro JM: Purification, cloning, and synthesis of a novel salivary anti-thrombin from the 
mosquito Anopheles albimanus. Biochemistry 1999 38: I|209-1|2|5.

4I. Francischetti IM, Valenzuela JG, Ribeiro JM: Anophelin: kinetics and mechanism of thrombin inhibition. Biochemistry 1999 , 38:16678-16685.

42. An. darlingi anophelin [http://exon.niaid.nih.gov/transcriptome/ A darlingi/T2/links/NR/AD-99-NR.txt]

43. Isawa $H$, Orito $Y$, Iwanaga $S$, Jingushi N, Morita A, Chinzei $Y$, Yuda M: Identification and characterization of a new kallikrein-kinin system inhibitor from the salivary glands of the malaria vector mosquito Anopheles stephens i. Insect Biochem Mol Biol 2007, 37:466-477.

44. An. darlingi anophensin [http://exon.niaid.nih.gov/transcriptome/ A darlingi/T2/links/NR/AD- /34-NR.txt]

45. Takac P, Nunn MA, Meszaros J, Pechanova O, Vrbjar N, Vlasakova P, Kozanek M, Kazimirova M, Hart G, Nuttall PA, Labuda M: Vasotab, a vasoactive peptide from horse fly Hybomitra bimaculata (Diptera, Tabanidae) salivary glands. J Exp Biol 2006, 209:343-352.

46. Xu X, Yang H, Ma D, Wu J, Wang Y, Song $Y$, Wang $X$, Lu Y, Yang J, Lai R: Toward an understanding of the molecular mechanism for successful blood feeding by coupling proteomics analysis with pharmacological testing of horsefly salivary glands. Mol Cell Proteomics 2008, 7:582-590.

47. Assumpcao TC, Francischetti IM, Andersen JF, Schwarz A, Santana JM, Ribeiro JM: An insight into the sialome of the blood-sucking bug Triatoma infestans, a vector of Chagas' disease. Insect Biochem Mol Biol 2008, 38:2 I 3-232.

48. Santos A, Ribeiro JM, Lehane MJ, Gontijo NF, Veloso AB, Sant'Anna MR, Nascimento Araujo R, Grisard EC, Pereira MH: The sialotranscriptome of the blood-sucking bug Triatoma brasiliensis (Hemiptera, Triatominae). Insect Biochem Mol Biol 2007 37:702-712.

49. Campbell CL, Vandyke KA, Letchworth G], Drolet BS, Hanekamp T, Wilson WC: Midgut and salivary gland transcriptomes of the arbovirus vector Culicoides sonorensis (Diptera: Ceratopogonidae). Insect Mol Biol 2005, I4:12I-136.

50. Campos IT, Amino R, Sampaio CA, Auerswald EA, Friedrich T, Lemaire HG, Schenkman S, Tanaka AS: Infestin, a thrombin inhibitor presents in Triatoma infestans midgut, a Chagas' disease vector: gene cloning, expression and characterization of the inhibitor. Insect Biochem Mol Biol 2002, 32:991-997.

5I. Campos IT, Tanaka-Azevedo AM, Tanaka AS: Identification and characterization of a novel factor XIla inhibitor in the hematophagous insect, Triatoma infestans (Hemiptera: Reduviidae). FEBS Lett 2004, 577:5 I2-5I6.

52. Lovato DV, Nicolau de Campos IT, Amino R, Tanaka AS: The fulllength cDNA of anticoagulant protein infestin revealed a novel releasable Kazal domain, a neutrophil elastase inhibitor lacking anticoagulant activity. Biochimie 2006, 88:673-68I.

53. Fink E, Rehm H, Gippner C, Bode W, Eulitz M, Machleidt W, Fritz H: The primary structure of bdellin B-3 from the leech Hirudo medicinalis. Bdellin B-3 is a compact proteinase inhibitor of a "non-classical" Kazal type. It is present in the leech in a high molecular mass form. Biol Chem Hoppe Seyler 1986, 367:1235-1242.

54. Muhlhahn P, Czisch M, Morenweiser R, Habermann B, Engh RA, Sommerhoff CP, Auerswald EA, Holak TA: Structure of leech derived tryptase inhibitor (LDTI-C) in solution. FEBS Lett 1994, 355:290-296.

55. Sommerhoff CP, Sollner C, Mentele R, Piechottka GP, Auerswald EA, Fritz $\mathrm{H}$ : A Kazal-type inhibitor of human mast cell tryptase: isolation from the medical leech Hirudo medicinalis, characterization, and sequence analysis. Biol Chem Hoppe Seyler 1994, 375:685-694.

56. Ramalho-Ortigao M, Jochim RC, Anderson JM, Lawyer PG, Pham VM, Kamhawi S, Valenzuela JG: Exploring the midgut transcriptome of Phlebotomus papatasi: comparative analysis of expression profiles of sugar-fed, blood-fed and Leishmania-majorinfected sandflies. BMC Genomics 2007, 8:300.

57. Jochim RC, Teixeira CR, Laughinghouse A, Mu J, Oliveira F, Gomes RB, Elnaiem DE, Valenzuela JG: The midgut transcriptome of Lutzomyia longipalpis: comparative analysis of cDNA libraries from sugar-fed, blood-fed, post-digested and Leishmania infantum chagasi-infected sand flies. BMC Genomics 2008, 9:15.
58. An. darlingi Kazal match I [http://exon.niaid.nih.gov/transcrip tome/A darlingi/T2/links/NR/AD-4/7-NR.txt]

59. An. darlingi Kazal link 2 [http://exon.niaid.nih.gov/transcriptome/ A darlingi/T2/links/NR/AD-257-NR.txt]

60. An. darlingi Kazal link 3 [http://exon.niaid.nih.gov/transcriptome/ A darlingi/T2/links/NR/AD-350-NR.txt]

61. Hang HC, Bertozzi CR: The chemistry and biology of mucintype O-linked glycosylation. Bioorg Med Chem 2005, I 3:5021-5034.

62. An. darlingi SG3 alleles [http://exon.niaid.nih.gov/transcriptome/ A darlingi/T2/links/cluster/anda-tb265-50-Sim-CLTL5.txt]

63. An. darlingi SG3 glycosylation sites [http://exon.niaid.nih.gov/ transcriptome/A darlingi/T2/links/netoglyc/AD-9-netoglyc.txt]

64. An. darlingi SG3 homologues [http://exon.niaid.nih.gov/transcrip tome/A darlingi/T2/links/SAL-DIP/AD-I0-SAL-DIP.txt]

65. Loomans HJ, Hahn BL, Li QQ, Phadnis SH, Sohnle PG: Histidinebased zinc-binding sequences and the antimicrobial activity of calprotectin. J Infect Dis 1998, 177:8|2-8|4.

66. Gusman H, Lendenmann U, Grogan J, Troxler RF, Oppenheim FG: Is salivary histatin 5 a metallopeptide? Biochim Biophys Acta 200I, 1545:86-95.

67. Rydengard V, Andersson Nordahl E, Schmidtchen A: Zinc potentiates the antibacterial effects of histidine-rich peptides against Enterococcus faecalis. Febs J 2006, 273:2399-2406.

68. An. darlingi gSGIO galactosylation sites [http://
[ exon.niaid.nih.gov/transcriptome/A darlingi/T2/links/netoglyc/AD145-netoglyc.txt]

69. An. darlingi gSGIO [http://exon.niaid.nih.gov/transcriptome/ A darlingi/T2/links/cluster/anda-tb275-50-Sim-CLTL9.txt]

70. An. darlingi gSGIO homologues [http://exon.niaid.nih.gov/tran scriptome/A darlingi/T2/links/NR/AD-/43-NR.txt]

7I. An. darlingi gSG 10 signature [http://exon.niaid.nih.gov/transcrip tome/A darlingi/T2/links/TICK-BLOCKS/AD-I43-TICKBLOCKS.txt]

72. An. darlingi $13.5 \mathrm{kDa}$ genes [http://exon.niaid.nih.gov/transcrip tome/A darlingi/T2/links/cluster/anda-tb235-50-Sim-CLTL3.txt]

73. An. darlingi $13.5 \mathrm{kDa}$ familygalactosylation sites [http:// exon.niaid.nih.gov/transcriptome/A darlingi/T2/links/netoglyc/AD46-netoglyc.txt

74. AD-9] homologues [http://exon.niaid.nih.gov/transcriptome/ A darlingi/T2/links/NR/AD-19|-NR.txt]

75. AD-9 I GO match [http://exon.niaid.nih.gov/transcriptome/ A darlingi/T2/links/GO/AD-19|-GO.txt]

76. An. darlingi perithrophin chitin bindingdomain [http:// exon.niaid.nih.gov/transcriptome/A darlingi/T2/links/PFAM/AD-873PFAM.txt]

77. An. darlingi perithrophin homologues [http://exon.niaid.nih.gov/ transcriptome/A darlingi/T2/links/NR/AD-873-NR.txt]

78. Shen Z, Jacobs-Lorena M: A type I peritrophic matrix protein from the malaria vector Anopheles gambiae binds to chitin. Cloning, expression, and characterization. J Biol Chem 1998, 273:17665-17670.

79. Ribeiro JMC: Role of arthropod saliva in blood feeding. Ann Rev Entomol 1987, 32:463-478

80. Champagne DE, Smartt CT, Ribeiro JM, James AA: The salivary gland-specific apyrase of the mosquito Aedes aegypti is a member of the 5'-nucleotidase family. Proc Natl Acad Sci USA 1995, 92:694-698.

81. Smartt CT, Kim AP, Grossman GL, James AA: The Apyrase gene of the vector mosquito, Aedes aegypti, is expressed specifically in the adult female salivary glands. Exp Parasitol 1995, 8I:239-248.

82. Sun D, McNicol A, James AA, Peng Z: Expression of functional recombinant mosquito salivary apyrase: $A$ potential therapeutic platelet aggregation inhibitor. Platelets 2006, 17:178-184.

83. An. darlingi 5'-nucleotidase orthologue [http:// exon.niaid.nih.gov/transcriptome/A darlingi/T2/links/NR/IS07-104NR.txt]

84. An. darlingi apyrase orthologue [http://exon.niaid.nih.gov/tran scriptome/A darlingi/T2/links/NR/AD-10I-NR.txt]

85. Ribeiro JM, Valenzuela JG: Purification and cloning of the salivary peroxidase/catechol oxidase of the mosquito Anopheles albimanus. J Exp Biol 1999, 202:809-816. 
86. Ribeiro JMC, Nussenzveig RH: The salivary catechol oxidasel peroxidase activities of the mosquito, Anopheles albimanus. J Exp Biol 1993, 179:273-287.

87. An. darlingi peroxidase homologues [http://exon.niaid.nih.gov/ transcriptome/A darlingi/T2/links/SAL-DIP/AD-573-SAL-DIP.txt]

88. Marinotti $O$, James A, Ribeiro JMC: Diet and salivation in female Aedes aegypti mosquitoes. J Insect Physiol 1990, 36:545-548.

89. Grossman GL, James AA: The salivary glands of the vector mosquito, Aedes aegypti, express a novel member of the amylase gene family. Insect Mol Biol 1993, I:223-232.

90. Marinotti O, de Brito M, Moreira CK: Apyrase and alpha-glucosidase in the salivary glands of Aedes albopictus. Comp Biochem Physiol B Biochem Mol Biol 1996, I I 3(4):675-679.

91. Grossman GL, Campos Y, Severson DW, James AA: Evidence for two distinct members of the amylase gene family in the yellow fever mosquito, Aedes aegypti. Insect Biochem Mol Biol I997, 27:769-78।.

92. James AA, Blackmer K, Racioppi JV: A salivary gland-specific, maltase-like gene of the vector mosquito, Aedes aegypti. Gene 1989, 75:73-83.

93. An. darlingi maltase homologues [http://exon.niaid.nih.gov/tran scriptome/A darlingi/T2/links/SAL-DIP/AD-70-SAL-DIP.txt]

94. An. darlingi salivary serine protease [http://exon.niaid.nih.gov/ transcriptome/A darlingi/T2/links/NR/AD-698-NR.txt]

95. An. darlingi gambicin [http://exon.niaid.nih.gov/transcriptome/ A darlingi/T2/links/NR/AD-23I-NR.txt]

96. An. darlingi defensin [http://exon.niaid.nih.gov/transcriptome/ A darlingi/T2/links/NR/AD-I24-NR.txt]

97. An. darlingi cecropins [http://exon.niaid.nih.gov/transcriptome/ A darlingi/T2/links/cluster/anda-tb235-50-Sim-CLTLI3.txt]

98. An. darlingi peptidoglycan recognition protein [http:// exon.niaid.nih.gov/transcriptome/A darlingi/T2/links/NR/AD-457NR.txt]

99. An. darlingi PMEI domain containing protein [http:// exon.niaid.nih.gov/transcriptome/A darlingi/TI/links/CDD/andacontig 859-CDD.txt]

100. An. darlingi lysozymes [http://exon.niaid.nih.gov/transcriptome/ A darlingi/T2/links/NR/AD- I74-NR.txt]

I0I. An. darlingi lysozyme [http://exon.niaid.nih.gov/transcriptome/ A darlingi/TI/links/SAL-DIP/anda-contig 443-SAL-DIP.txt]

102. An. darlingi Gly rich protein [http://exon.niaid.nih.gov/transcrip tome/A darlingi/T2/links/SAL-DIP/AD-259-SAL-DIP.txt]

103. Megraw T, Kaufman TC, Kovalick GE: Sequence and expression of Drosophila Antigen 5-related 2, a new member of the CAP gene family. Gene 1998, 222:297-304.

104. Milne TJ, Abbenante G, Tyndall JD, Halliday J, Lewis RJ: Isolation and characterization of a cone snail protease with homology to CRISP proteins of the pathogenesis-related protein superfamily. J Biol Chem 2003, 278:3। I05-3।III0.

105. Mochca-Morales J, Martin BM, Possani LD: Isolation and characterization of helothermine, a novel toxin from Heloderma horridum horridum (Mexican beaded lizard) venom. Toxicon 1990, 28:299-309.

106. Nobile M, Noceti F, Prestipino G, Possani LD: Helothermine, a lizard venom toxin, inhibits calcium current in cerebellar granules. Exp Brain Res 1996, I 1 0:15-20.

107. Yamazaki Y, Hyodo F, Morita T: Wide distribution of cysteinerich secretory proteins in snake venoms: isolation and cloning of novel snake venom cysteine-rich secretory proteins. Arch Biochem Biophys 2003, 4I 2: I33-141.

108. Yamazaki $Y$, Koike H, Sugiyama $Y$, Motoyoshi K, Wada T, Hishinuma $S$, Mita M, Morita T: Cloning and characterization of novel snake venom proteins that block smooth muscle contraction. Eur JBiochem 2002, 269:2708-27I5.

109. Yamazaki $Y$, Morita T: Structure and function of snake venom cysteine-rich secretory proteins. Toxicon 2004, 44:227-231.

110. Stintzi A, Heitz T, Prasad V, Wiedemann-Merdinoglu S, Kauffmann S, Geoffroy P, Legrand M, Fritig B: Plant 'pathogenesis-related' proteins and their role in defense against pathogens. Biochimie 1993, 75:687-706.

III. An. darlingi antigen-5 members [http://exon.niaid.nih.gov/tran scriptome/A darlingi/T2/links/cluster/anda-tb255-50-SimCLTL28.txt]

112. An. darlingi AG-5 orthologue of An. gambiae [http:// exon.niaid.nih.gov/transcriptome/A darlingi/T2/links/NR/AD-38NR.txt]
II3. An. darlingi second Ag-5 [http://exon.niaid.nih.gov/transcriptome/ A darlingi/T2/links/NR/AD-430-NR.txt]

I14. An. gambiae gSG5 [http://www.ncbi.nlm.nih.gov/sutils/ blink.cgi?pid= I3537662

II5. Lanfrancotti A, Lombardo F, Santolamazza F, Veneri M, Castrignano T, Coluzzi M, Arca B: Novel cDNAs encoding salivary proteins from the malaria vector Anopheles gambiae. FEBS Lett 2002 , 5 I 7:67-7|

I16. gSG5 members [http://www.ncbi.nlm.nih.gov/blast/bl2seq/ wblast2.cgi?one $=\mid 3537662 \&$ two $=94468640 \&$ prot $=$ blastp\&expect $=3$ 00]

117. gSG5 and Aedes [http://www.ncbi.nlm.nih.gov/blast/bl2seq/ wblast 2. cgi?one $=\mid 3537662 \&$ two $=|0888| 4|| \mid$ \&prot $=$ blastp\&expect $=$ 300]

I18. gSG5 and Culex [http://www.ncbi.nlm.nih.gov/blast/bl2seq/ wblast2.cgi?one $=\mid 3537662 \&$ two $=167867902 \&$ prot $=$ blastp\&expect $=$ 300]

II9. An. darlingi gSG5 [http://exon.niaid.nih.gov/transcriptome/ A darlingi/T2/links/NR/AD-196-NR.txt]

120. An. darlingi gSG8 [http://exon.niaid.nih.gov/transcriptome/ A darlingi/T2/links/SAL-DIP/AD-178-SAL-DIP.txt]

121. An. darlingi basic tail proteins [http://exon.niaid.nih.gov/tran scriptome/A darlingi/T2/links/cluster/anda-tb285-50-SimCLTL20.txt]

122. An. darlingi basic tail matches [http://exon.niaid.nih.gov/tran scriptome/A darlingi/T2/links/NR/AD-217-NR.txt]

123. AD-476 homologues [http://exon.niaid.nih.gov/transcriptome/ A darlingi/T2/links/NR/AD-476-NR.txt]

124. Proline rich peptides [http://www.ncbi.nlm.nih.gov/sutils/ blink.cgi?pid $=94468394]$

125. AD-267 proline rich polypeptide [http://exon.niaid.nih.gov/tran scriptome/A darlingi/T2/links/SAL-DIP/AD-267-SAL-DIP.txt]

126. 41.9 kDa family [http://www.ncbi.nlm.nih.gov/sutils/ blink.cgi?pid=3835063i]

127. An. darlingi $41.9 \mathrm{kDa}$ family member [http://exon.niaid.nih.gov/ transcriptome/A darlingi/T2/links/NR/AD-I|4-NR.txt]

128. 4I.9 kDa Psiblast [http://exon.niaid.nih.gov/transcriptome/ A darlingi/Psi-4I.pdf]

129. Anderson JM, Oliveira F, Kamhawi S, Mans BJ, Reynoso D, Seitz AE, Lawyer P, Garfield M, Pham M, Valenzuela JG: Comparative salivary gland transcriptomics of sandfly vectors of visceral leishmaniasis. BMC Genomics 2006, 7:52.

130. Oliveira F, Kamhawi S, Seitz AE, Pham VM, Guigal PM, Fischer L, Ward J, Valenzuela JG: From transcriptome to immunome: identification of DTH inducing proteins from a Phlebotomus ariasi salivary gland cDNA library. Vaccine 2006, 24:374-390.

13।. Calvo E, Pham VM, Ribeiro JM: An insight into the sialotranscriptome of the non-blood feeding Toxorhynchites amboinensis mosquito. Insect Biochem Mol Biol 2008, 38:499-507.

132. An. gambiae SG I cluster [http://exon.niaid.nih.gov/transcriptome/ An gambiae sialome-2005/Fig5.pdf]

133. An. darlingi 41.9 kDa variants [http://exon.niaid.nih.gov/transcrip tome/A darlingi/T2/links/cluster/anda-tb295-50-Sim-CLTL24.txt]

134. Clade III of 41.9 kDa family [http://exon.niaid.nih.gov/transcrip tome/A darlingi/T2/links/cluster/anda-tb285-50-Sim-CLTLI5.txt]

135. Calvo E, Pham VM, Lombardo F, Arca B, Ribeiro JM: The sialotranscriptome of adult male Anopheles gambiae mosquitoes. Insect Biochem Mol Biol 2006, 36:570-575.

136. An. darlingi SG2 alleles [http://exon.niaid.nih.gov/transcriptome/ A darlingi/T2/links/cluster/anda-tb295-50-Sim-CLTL4.txt]

137. SG2 second gene [http://exon.niaid.nih.gov/transcriptome/ A darlingi/T2/links/cluster/anda-tb255-50-Sim-CLTL5.txt]

138. SG2 match I [http://exon.niaid.nih.gov/transcriptome/A darlingi/ T2/links/SAL-DIP/AD-92-SAL-DIP.txt]

139. SG2 match 2 [http://exon.niaid.nih.gov/transcriptome/A darlingi/ T2/links/SAL-DIP/AD-90-SAL-DIP.txt]

140. Hyp I5/17 genes [http://exon.niaid.nih. gov/transcriptome/ A darlingi/T2/links/cluster/anda-tb285-50-Sim-CLTL9.txt]

141. Hyp I5/17 matches [http://exon.niaid.nih.gov/transcriptome/ A darlingi/T2/links/SAL-DIP/AD-37-SAL-DIP.txt]

142. An. darlingi hyp8.2/hyp6.2 family [http://exon.niaid.nih.gov/tran scriptome/A darlingi/T2/links/cluster/anda-tb235-50-SimCLTL29.txt]

143. An. darlingi hyp8.2 [http://exon.niaid.nih.gov/transcriptome/ A darlingi/T2/links/SAL-DIP/AD-63-SAL-DIP.txt] 
144. An. darlingi hyp6.2 [http://exon.niaid.nih.gov/transcriptome/ A darlingi/T2/links/SAL-DIP/AD-I47-SAL-DIP.txt]

145. An. darlingi hyp5.6 [http://exon.niaid.nih.gov/transcriptome/ A darlingi/T2/links/SAL-DIP/AD-269-SAL-DIP.txt]

146. An. darlingi 2WIRRP genes [http://exon.niaid.nih.gov/transcrip tome/A darlingi/T2/links/cluster/anda-tb265-50-Sim-CLTL3.txt]

147. An. darlingi 2WIRRP alleles [http://exon.niaid.nih.gov/transcrip tome/A darlingi/T2/links/cluster/anda-tb285-50-Sim-CLTL3.txt]

148. 2WIRRP An. gambiae match I [http://exon.niaid.nih.gov/tran scriptome/A darlingi/T2/links/SAL-DIP/AD-I8-SAL-DIP.txt]

149. 2WIRRP An. gambiae match 2 [http://exon.niaid.nih.gov/tran scriptome/A darlingi/T2/links/SAL-DIP/AD-I5-SAL-DIP.txt]

150. An. darlingi orphan I [http://exon.niaid.nih.gov/transcriptome/ A darlingi/T2/links/NR/AD-I36-NR.txt]

15I. AD-136 alleles [http://exon.niaid.nih.gov/transcriptome/ A darlingi/T2/links/cluster/anda-tb295-50-Sim-CLTL9.txt]

152. gSG6 family absent in An. darlingi [http://www.ncbi.nlm.nih.gosutils/blink.cgi?pid=| 35376668itool=EntrezSystem2.PEntrez.Pro tein.Sequence ResultsPanel.Sequence RVDocSum\&ordinalpos $=1$ ]

153. hyp 10 and hyp $/ 2$ absent proteins [http://www.ncbi.nlm.nih.gosutils/blink.cgi?.pid $=|838990|$ \&itool $=$ EntrezSystem2.PEntrez.Pro tein.Sequence ResultsPanel.Sequence RVDocSum\&ordinalpos $=1$ ]

154. Krzywinski J, Besansky NJ: Molecular systematics of Anopheles: from subgenera to subpopulations. Annu Rev Entomol 2003, 48:111-139.

155. Cornelie S, Remoue F, Doucoure S, Ndiaye T, Sauvage FX, Boulanger $D$, Simondon F: An insight into immunogenic salivary proteins of Anopheles gambiae in African children. Malar J 2007, 6:75.

156. Orlandi-Pradines E, Almeras L, Denis de Senneville L, Barbe S, Remoue F, Villard C, Cornelie S, Penhoat K, Pascual A, Bourgouin C, Fontenille D, Bonnet J, Corre-Catelin N, Reiter P, Pages F, Laffite D, Boulanger D, Simondon F, Pradines B, Fusai T, Rogier C: Antibody response against saliva antigens of Anopheles gambiae and Aedes aegypti in travellers in tropical Africa. Microbes Infect 2007, 9: I 454-I 462.

157. Poinsignon A, Cornelie S, Mestres-Simon M, Lanfrancotti A, Rossignol M, Boulanger D, Cisse B, Sokhna C, Arca B, Simondon F, Remoue F: Novel peptide marker corresponding to salivary protein gSG6 potentially identifies exposure to Anopheles bites. PLOS ONE 2008, 3:e2472.

158. Remoue F, Cisse B, Ba F, Sokhna C, Herve JP, Boulanger D, Simondon $F$ : Evaluation of the antibody response to Anopheles salivary antigens as a potential marker of risk of malaria. Trans $R$ Soc Trop Med Hyg 2006, 100:363-370.

159. Lanzaro GC, Lopes AH, Ribeiro JM, Shoemaker CB, Warburg A, Soares M, Titus RG: Variation in the salivary peptide, maxadilan, from species in the Lutzomyia longipalpis complex. Insect Mol Biol 1999, 8:267-275.

160. Mans BJ, Andersen JF, Francischetti IM, Valenzuela JG, Schwan TG, Pham VM, Garfield MK, Hammer CH, Ribeiro JM: Comparative sialomics between hard and soft ticks: Implications for the evolution of blood-feeding behavior. Insect Biochem Mol Biol 2008, 38:42-58.

161. Mans BJ, Andersen JF, Schwan TG, Ribeiro JM: Characterization of anti-hemostatic factors in the argasid, Argas monolakensis: Implications for the evolution of blood-feeding in the soft tick family. Insect Biochem Mol Biol 2008, 38:22-4I.

162. Koressaar T, Remm M: Enhancements and modifications of primer design program Primer3. Bioinformatics 2007. 23:|289-|29|.

163. Huang $X$, Madan A: CAP3: A DNA sequence assembly program. Genome Res 1999, 9:868-877.

164. Thompson JD, Gibson TJ, Plewniak F, Jeanmougin F, Higgins DG: The CLUSTAL $X$ windows interface: flexible strategies for multiple sequence alignment aided by quality analysis tools. Nucleic Acids Res 1997, 25:4876-4882.

165. Kumar S, Tamura K, Nei M: MEGA3: Integrated software for Molecular Evolutionary Genetics Analysis and sequence alignment. Brief Bioinform 2004, 5:150-163.

166. Bateman A, Birney E, Durbin R, Eddy SR, Howe KL, Sonnhammer EL: The Pfam protein families database. Nucleic Acids Res 2000, 28:263-266.

167. Letunic I, Goodstadt L, Dickens NJ, Doerks T, Schultz J, Mott R, Ciccarelli F, Copley RR, Ponting CP, Bork P: Recent improvements to the SMART domain-based sequence annotation resource. Nucleic Acids Res 2002, 30:242-244.
168. Tatusov RL, Fedorova ND, Jackson JD, Jacobs AR, Kiryutin B, Koonin EV, Krylov DM, Mazumder R, Mekhedov SL, Nikolskaya AN, Rao BS, Smirnov S, Sverdlov AV, Vasudevan S, Wolf YI, Yin JJ, Natale DA: The COG database: an updated version includes eukaryotes. BMC Bioinformatics 2003, 4:4I.

169. Nielsen H, Engelbrecht J, Brunak S, von Heijne G: Identification of prokaryotic and eukaryotic signal peptides and prediction of their cleavage sites. Protein Eng 1997, 10:1-6.

170. Julenius K, Molgaard A, Gupta R, Brunak S: Prediction, conservation analysis, and structural characterization of mammalian mucin-type O-glycosylation sites. Glycobiology 2005, 15:153-164.

Publish with Biomed Central and every scientist can read your work free of charge

"BioMed Central will be the most significant development for disseminating the results of biomedical research in our lifetime. "

Sir Paul Nurse, Cancer Research UK

Your research papers will be:

- available free of charge to the entire biomedical community

- peer reviewed and published immediately upon acceptance

- cited in PubMed and archived on PubMed Central

- yours - you keep the copyright
BioMedcentral 